NBER WORKING PAPER SERIES

\title{
INDUSTRY COMPENSATION UNDER RELOCATION RISK: A FIRM-LEVEL ANALYSIS OF THE EU EMISSIONS TRADING SCHEME
}

\author{
Ralf Martin \\ Mirabelle Muûls \\ Laure B. de Preux \\ Ulrich J. Wagner \\ Working Paper 19097 \\ http://www.nber.org/papers/w19097 \\ NATIONAL BUREAU OF ECONOMIC RESEARCH \\ 1050 Massachusetts Avenue \\ Cambridge, MA 02138 \\ June 2013
}

We are indebted to Barry Anderson, Jörg Leib and Marty McGuigan for their invaluable help at different stages of this research, and to Felix de Bousies, Pieter De Vlieger, David Disch, Eszter Domokos, Lorenz Elsasser, Helen Franzen, Maite Kervyn, Zsofia Kopetka, Oliwia Kurtyka, Anne-Lise Laurain, Emeric Lujan, Nicole Polsterer, Antoine Martin-Regniault, Maxence Snoy, Joanna Romanowicz, Bartosz $\mathrm{Vu}$, Julia Wittig, Joanna Wylegala for their help with the interviews. Melanie Hermann and Antonin Cura provided excellent research assistance. The constructive and insightful comments by two anonymous referees, by the editor, and by Mark Jacobsen have led to a much improved paper. We have received helpful comments from Stephen Boucher, Alex Bowen, Jonathan Colmer, Denny Ellerman, Sam Fankhauser, Tom Foxon, Andy Gouldson, Stéphanie Monjon, John Van Reenen and from staff members at DECC, at DG Climate, and at the Environmental Committee of the European Parliament. We thank conference participants at A Toxa 2012, EEA 2011, NBER Summer Institute 2012, RES 2012, SURED 2012, WCERE 2010, and seminar audiences at Carlos III, Düsseldorf Institute for Competition Economics, Kiel University, LSE, Münster University, the Paris Environmental and Energy Economics Seminar and RWTH Aachen for their feedback. All remaining errors are our own. The interviews were funded through grants from the European Climate Foundation and the ESRC. The Centre for Economic Performance and the Grantham Institute on Climate Change provided generous logistical support. The authors gratefully acknowledge financial support from the British Academy (Martin), from the Leverhulme Trust (Muûls) and from the Spanish Ministry for Science and Innovation, reference number SEJ2007-62908 (Wagner). The views expressed herein are those of the authors and do not necessarily reflect the views of the National Bureau of Economic Research.

At least one co-author has disclosed a financial relationship of potential relevance for this research. Further information is available online at http://www.nber.org/papers/w19097.ack

NBER working papers are circulated for discussion and comment purposes. They have not been peerreviewed or been subject to the review by the NBER Board of Directors that accompanies official NBER publications.

(C) 2013 by Ralf Martin, Mirabelle Muûls, Laure B. de Preux, and Ulrich J. Wagner. All rights reserved. Short sections of text, not to exceed two paragraphs, may be quoted without explicit permission provided that full credit, including (C) notice, is given to the source. 
Industry Compensation Under Relocation Risk: A Firm-Level Analysis of the EU Emissions

Trading Scheme

Ralf Martin, Mirabelle Muûls, Laure B. de Preux, and Ulrich J. Wagner

NBER Working Paper No. 19097

June 2013

JEL No. F18,H23,H25,Q52,Q54

\begin{abstract}
When regulated firms are offered compensation to prevent them from relocating, efficiency requires that payments be distributed across firms so as to equalize marginal relocation probabilities, weighted by the damage caused by relocation. We formalize this fundamental economic logic and apply it to analyzing compensation rules proposed under the EU Emissions Trading Scheme, where emission permits are allocated free of charge to carbon intensive and trade exposed industries. We show that this practice results in substantial overcompensation for given carbon leakage risk. Efficient permit allocation reduces the aggregate risk of job loss by more than half without increasing aggregate compensation.
\end{abstract}

\section{Ralf Martin}

Imperial College Business School

London School of Economics

London SW7 2AZ

United Kingdom

and Centre for Economic Performance, LSE

R.Martin@1se.ac.uk

Mirabelle Muûls

Grantham Institute for Climate Change

and Imperial College Business School

South Kensington Campus

London SW7 2AZ

United Kingdom

and and Centre for Economic Performance, LSE

m.muuls@imperial.ac.uk
Laure B. de Preux

Centre for Health Economics

University of York

Heslington

York YO10 5DD, UK

and Centre for Economic Performance, LSE

L.B.dePreux@lse.ac.uk

Ulrich J. Wagner

Universidad Carlos III de Madrid

Department of Economics

Calle de Madrid, 126

28903 Getafe (Madrid)

Spain

uwagner@eco.uc3m.es

An online appendix is available at:

http://www.nber.org/data-appendix/w19097 


\section{Introduction}

Government intervention in the marketplace is often justified as a means to increase net social welfare. When imposing welfare-improving regulation, a benevolent government may be able to tax part of the welfare gains and use the revenue to compensate industry for the cost of compliance. But when should compensation be offered, to whom, and how much? Should firms that pollute the environment be offered compensation for the cost impact of a regulation that forces them to internalize the environmental damage? Should financial institutions be offered compensation for a tax levied on financial transactions?

The distributional effects of regulation have far-reaching consequences for policy design. If no compensation is offered, industry has incentives to spend large amounts on raising political support against the policy, and to lobby for exemption clauses that weaken the policy's effectiveness. Worse, when the policy is not harmonized across jurisdictions, firms may find it profitable to relocate to an unregulated one. As the head of a leading financial transactions company recently told the BBC: "If [the financial transaction tax] really happened, we would have to move our business to New York or Singapore or Hong Kong. Our business would continue. [It is] just sad it wouldn't continue in London."1 The threat of relocation - if credible - is a powerful argument to extract concessions from politicians of all stripes, as regulation-induced job losses are likely to cloud their re-election prospects.

In the realm of climate policy, the threat of relocation is aggravated by "carbon leakage", i.e. the phenomenon that industrial relocation shifts greenhouse gas (GHG) emissions to places beyond the regulator's reach. Since GHG emissions are a global

\footnotetext{
${ }^{1} \mathrm{BBC}$ interview with Michael Spencer, Group Chief Executive Officer of ICAP, available online at http://www.bbc.co.uk/news/business-16990025.
} 
public bad, relocation not only costs jobs at home but also weakens the environmental effectiveness of the policy. It is therefore not surprising that generous compensations are pervasive in this area. ${ }^{2}$ For example, numerous European countries have implemented carbon taxes since the 1990's, and virtually all of them grant rebates or exemptions to energy-intensive firms, even though this practice runs counter to the polluter-pays principle underlying environmental policy-making in the EU.

This paper demonstrates that an efficient compensation structure is characterized by offering compensation first to those firms where it leads to the highest marginal improvement in the government's objective function associated with the policy. This is different from compensating the firms with the highest propensity to relocate. Rather, an efficient compensation rule equalizes, across firms, the firms' marginal propensity to relocate, weighted by how damaging their relocation is to the government's objectives.

We analyze the implications of this idea in the context of industry compensation rules established under the European Union Emissions Trading System (EU ETS), the largest cap-and-trade system worldwide. The EU ETS imposes an overall cap on $\mathrm{CO}_{2}$ emissions from stationary sources - mostly power stations and industrial plants - in 31 countries. Emitters with heterogeneous abatement costs can trade permits amongst each other or with third parties so as to lower their total abatement cost and hence, the total cost of complying with the cap on $\mathrm{CO}_{2}$. Since the beginning of the EU ETS in 2005, industrial emitters have been compensated for the cost of compliance by re-

\footnotetext{
${ }^{2}$ The evidence on whether the threat of relocation is credible is very scant when it comes to climate policy. Martin, de Preux, and Wagner (2011a) find no evidence that the UK Climate Change Levy caused output reductions or plant exit among treated firms. The literature on foreign direct investment and more broadly-defined environmental regulation suggests that relocation decisions in some industries are indeed deterred by environmental regulatory stringency (e.g. Wagner and Timmins, 2009; Hanna, 2010b).
} 
ceiving fairly generous allocations of free permits based on their past $\mathrm{CO}_{2}$ emissions. Contrary to its initial plan of phasing in auctioning of permits from 2013, the European Commission (EC) has decided in 2009 that free permit allocation will be continued for industries deemed at a heightened risk of carbon leakage. Determining which industries are at risk is complicated by asymmetric information about compliance costs. Regulated firms face an incentive to exaggerate these costs in order to extract more rents in the form of free permits, or to lobby for a more lenient overall cap. The EC decided to exempt from permit auctions industries that are either very carbon intensive or very trade exposed, or that exceed certain threshold values on both measures. There is, however, no empirical evidence that these exemption criteria are in any way related to actual relocation or downsizing risk, let alone the marginal impacts of compensation on such risk.

This paper provides the first evidence on this topic based on new firm-level data we gathered in telephone interviews with managers of 761 manufacturing firms in six European countries. We applied a new survey tool developed recently by Bloom and van Reenen (2007) with the objective to mitigate known types of bias arising in conventional survey formats. The method allows us to elicit information on politically contentious issues such as firms' propensity to downsize or relocate in response to climate change policy. In all six countries and in most industries we studied, firms report an average downsizing risk well below a $10 \%$ cut in production or employment. In none of the industries did we find that the average firm will close down entirely and relocate to a non-European country. There is, however, substantial variation in the reported vulnerability between sectors as well as individual firms. This indicates that the EU's approach of exempting entire industries from permit auctions may not be efficient. 
We explore this idea by developing a normative framework for industry compensation under the threat of relocation. Since free permits are revoked and cancelled when a firm exits, we assume that the propensity to relocate is declining in the amount of free permits a firm receives. The government allocates a fixed amount of permits so as to minimize the sum of relocation propensities across firms, weighted by the damage caused by relocation. This amounts to minimizing the aggregate expected damage of relocation. When damage is expressed in terms of $\mathrm{CO}_{2}$ emissions, this objective function formalizes the EC's notion of 'carbon leakage risk'. An alternative specification we consider minimizes 'job risk', i.e. the expected amount of jobs lost due to relocation.

The upshot of the model is that efficiency requires that free permits be given to those firms where they have the highest marginal impact on total relocation risk (i.e. carbon leakage or job risk). Using the interview data, we show that this marginal impact varies substantially across firms and sectors, and that it is not necessarily correlated with the impact level. Counterfactual simulations reveal that optimal allocation dramatically reduces relocation risk, even compared to the situation where all permits are handed out for free. We also consider the dual problem of minimizing the number of permits handed out for free while constraining relocation risk. We find that the amount of relocation risk induced by the allocation rules for phase III of the EU ETS could be achieved with just a fraction of the amount of permits that will be handed out for free. The mismatch between optimal and actual allocations is particularly severe when it comes to minimizing job risk. Thus, although the exemption criteria were designed to protect the competitiveness of the most vulnerable industries, they do little to mitigate the expected employment impact of carbon pricing.

A practical difficulty with implementing this optimal firm-level compensation scheme 
is that firms' vulnerability to carbon pricing is not publicly observable. We therefore derive optimal permit allocations under the 'feasibility constraint' that the allocation rule is a function of easily observable firm characteristics. We find that even simple rules, based on firm-level employment and carbon emissions alone, substantially reduce both carbon leakage risk and job risk.

Finally, we analyze the current practice of exempting entire sectors from permit auctions based on their carbon and trade intensities. We show that carbon intensity is strongly correlated with our interview-based measure of vulnerability whereas trade intensity is not. This is a reason for concern because most exemptions from auctioning will be granted on the basis of the trade intensity criterion alone. We propose two alternatives to the current exemption criteria, based on the principle that free permits should only be given to industries where the average relocation risk is significantly higher than that of non-exempt industries. First, by not exempting trade intensive sectors but the ones that are at least moderately carbon intensive as well, European governments could raise additional auction revenue in the order of $€ 3$ billion every year. Second, we show that a sector's intensity of trade with less developed countries such as China is a better proxy for vulnerability than the overall trade intensity. A change in the definition of the trade intensity criterion along these lines could raise an additional $€ 430$ million in auction revenues per year.

Our analysis of the efficiency of free permit allocation in the EU ETS contributes important evidence pertaining to a difficult and contentious policy issue. Overcompensating carbon-intensive industries in times of broad public spending cuts might nourish a political backlash against emissions trading. The evidence presented in this paper will inform the EC's revision of the exemption criteria, envisioned for 2014, but its relevance transcends the European policy context. The EU ETS - and in partic- 
ular its approach to preventing industrial relocation and carbon leakage - serves as a prototype for new and emerging regional trading schemes worldwide. Specifically, Australia, California, Korea, New Zealand, and Switzerland have already adopted the EU's exemption criteria with minimal changes. Therefore, it is important to analyze how accurately these criteria identify the firms and sectors most vulnerable to carbon leakage.

The next section describes the process of free permit allocation in the EU ETS and summarizes the related literature. Section 3 describes the data set, particularly how we measure firm-level vulnerability to carbon pricing. Section 4 presents a normative framework for optimal permit allocation under relocation risk and conducts several counterfactual experiments under alternative constraints. Section 5 analyzes the current, sector-level exemption criteria. Section 6 concludes.

\section{Permit allocation in the EU ETS}

Designing a cap-and-trade scheme inevitably requires a choice to be made about the initial allocation of permits. Unless all permits are auctioned off, the regulator has to determine the micro-allocation of permits across firms, across sectors, and - in an international emissions trading scheme such as the EU ETS - across countries. Initial permit allocation in phases I and II of the EU ETS followed a decentralized process. Countries were called upon to draw up National Allocation Plans that both fixed the national cap and determined the sectoral allocation. The majority of countries chose to "grandfather" existing business sites, i.e. they allocated emission permits for free based on historical emissions and adjusted for growth projections and the national 
contribution towards the EU's joint emission target under the Kyoto Protocol. ${ }^{3}$ Free allowances were granted to new entrants whereas the allowances of exiting facilities were revoked and cancelled.

For trading phase III, beginning in 2013, the EC envisioned a transition towards auctioning as the basic principle of allocation, which would transfer the ownership of emissions from incumbent polluters back to governments and, ultimately, taxpayers. Directive 2009/29/EC relegates the allocation of free emission allowances from national governments to Brussels and stipulates a harmonized allocation scheme to reduce competitive distortions among producers of similar products across member states. In what follows, we explain the two main features of this scheme, namely (i) the use of benchmarks which rewards operators who have taken early action to reduce the emission intensity of production and (ii) the continued free allocation to sectors considered at risk of carbon leakage.

\subsection{Benchmarking}

The Benchmarking Decision ${ }^{4}$ stipulates that free allocation be based on product benchmarks to the extent possible. A product benchmark is defined as the average greenhouse gas emission performance of the $10 \%$ best performing installations in the EU producing that product, measured in tons of $\mathrm{CO}_{2}$ equivalent per unit of output. An installation $i$ producing an eligible benchmarked product $j$ in year $t$ receives an allocation

\footnotetext{
${ }^{3}$ Ellerman et al. (2007) document that the principles guiding the development of National Allocation Plans in phase I were rather consistent across countries, as most opted for free permit allocations based on existing emissions. In phase II, governments imposed more stringent caps while retaining the allocation scheme. Auctioning fell far short of what was allowed and benchmarking remained an exception (Ellerman and Joskow, 2008).

${ }^{4}$ Commission Decision 2011/87/EU determining transitional Union-wide rules for harmonised free allocation of emission allowances pursuant to Article 10a of Directive 2003/87/EC of the European Parliament and of the Council (2011) OJ L 130/1 (Benchmarking Decision).
} 
of free permits given by

$$
q_{i j t}^{b}=\text { benchmark }_{j} \cdot \text { historical activity } \operatorname{level}_{i, j} \cdot \text { reduction }_{j, t} \cdot \operatorname{correction}_{t} .
$$

The benchmark of product $j$ is based on the average emissions intensity in 2007-2008. The historical reference activity level is the median activity level over the years from 2005 until 2008 (or from 2009 until 2010, if larger). The number of free permits resulting from the first two terms in eq. (1) is scaled by two factors. First, the reduction factor takes a value of 0.8 in 2013 and declines linearly to a factor of 0.3 in 2020 . No reduction occurs in sectors considered at risk of carbon leakage, for which the factor takes a value of 1 in all years. Second, a uniform correction factor is applied if necessary to align the total free allocation to benchmarked installations with the overall cap on emissions.

Where deriving a product benchmark is not feasible, allowances are allocated according to a hierarchy of fallback approaches. If a measurable heat carrier is used, benchmarks apply to heat consumption, otherwise they are tied to fuel consumption. If none of these approaches is feasible, the relevant benchmark is given by 0.97 times historical process emissions. Complex installations requiring various benchmarking techniques are first divided into sub-installations for which a single relevant benchmark can be used to determine allowance allocations.

A distinctive feature of the EU ETS is that free permit allocation is not tied to current production levels. ${ }^{5}$ Rather, allowance allocation is based on production capacity prior to the trading phase and annual updates occur automatically via the linearly de-

\footnotetext{
${ }^{5}$ In contrast, carbon trading schemes in Australia, California or New Zealand establish "output based updating" where the benchmark is scaled by current output (Hood, 2010). The US case is analyzed by Burtraw et al. (2001); Bushnell and Chen (2009); Fischer and Fox (2007); Fowlie (2011). Monjon and Quirion (2011) analyze a hypothetical output based updating rule for the EU ETS.
} 
creasing reduction factor. Only under exceptional circumstances do production choices entail an adjustment to the allowance allocation. On the one hand, if production drops by at least $50 \%$ relative to the historical activity level, a $50 \%$ reduction is applied to the free allowance allocation. If activity falls below $90 \%$, free allocation will be ceased. On the other hand, in order to increase its permit allocation, an installation must undergo a net capacity increase of $15 \%$ or more, accompanied by a "significant increase in activity". New entrants receive free permit allocations according to the relevant benchmark, and activity levels are proxied for by multiplying the initial installed capacity by a standard capacity utilization factor. Compared to output-based updating, the capacity-based allocation rules in the EU ETS substantially limit an operator's ability to influence permit allocations by changing output and hence the impact of permit allocation on short-run production decisions (Ellerman, 2008; Meunier et al., 2012).

\subsection{Free allocation to sectors deemed at risk of carbon leakage}

The gradual reduction in free allowances from $80 \%$ to $30 \%$ was met with strong opposition from carbon intensive industries, who convinced EU law makers that full auctioning of permits would exacerbate the detrimental impact of the EU ETS on their competitiveness. In order to mitigate such impacts, the EC will grant $100 \%$ of benchmark allocations for free to firms in sectors that are considered at risk of carbon leakage. The Carbon Leakage Decision ${ }^{6}$ establishes leakage risk of a sector or subsector based on its carbon intensity (CI) and/or trade intensity (TI). CI proxies for the cost burden imposed by full auctioning, and is measured as the sum of the direct and indirect costs of permit auctioning, divided by the gross value added of a sector. The

\footnotetext{
${ }^{6}$ Commission Decision 2010/2/EU determining, pursuant to Directive 2003/87/EC of the European Parliament and of the Council, a list of sectors and subsectors which are deemed to be exposed to a significant risk of carbon leakage (2010) OJ L 1/10 (Carbon Leakage Decision).
} 
Figure 1: Sectors exempt from permit auctions

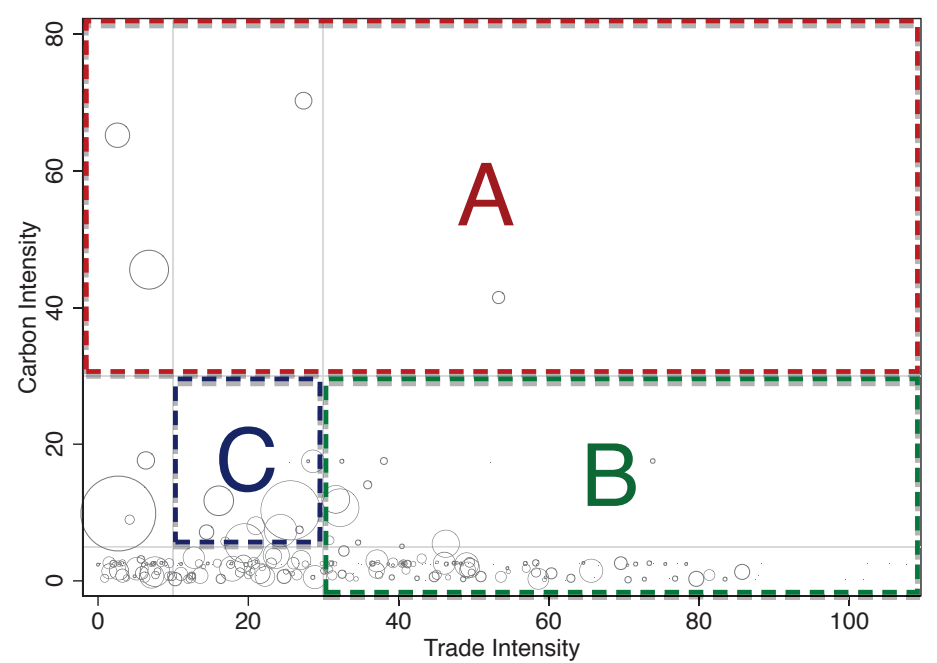

Notes: The figure shows a scatter plot of the carbon and trade intensities of 4-digit (NACE 1.1) manufacturing industries, based on 9,061 EU ETS installations. The size of the circles is proportional to the number of firms in a given industry. Sectors in areas $\mathrm{A}, \mathrm{B}$, and $\mathrm{C}$ will continue to be exempt from permit auctions in EU ETS phase III.

direct costs are calculated as the value of direct $\mathrm{CO}_{2}$ emissions (using a proxy price of $\left.30 € / t \mathrm{CO}_{2}\right)$. The indirect costs capture the exposure to electricity price rises that are inevitable on account of full permit auctioning in the power sector. ${ }^{7}$ The TI metric is calculated as "the ratio between the total value of exports to third countries plus the value of imports from third countries and the total market size for the Community (annual turnover plus total imports from third countries" (EU Commission, 2009, p. 24).

Directive 2009/29/EC stipulates a combination of thresholds for CI and TI to determine if a sector is at risk of carbon leakage. Sectors are considered at significant risk of carbon leakage if their CI is greater than $5 \%$ and their TI is greater than $10 \%$, or either CI or TI is greater than $30 \%$. We subdivide eligible sectors accordingly into three

\footnotetext{
${ }^{7}$ They are calculated as electricity consumption (in MWh) multiplied by the average emission intensity of electricity generation in the EU27 countries $\left(0.465 \mathrm{tCO}_{2} / \mathrm{MWh}\right)$, and applying the same proxy price for an European Union Allowance of $30 € / \mathrm{tCO}_{2}$.
} 
mutually exclusive categories: A - high carbon intensity $(\mathrm{CI}>30 \%), \mathrm{B}-$ high trade intensity and low to moderate carbon intensity $(\mathrm{CI} \leq 30 \% \cap \mathrm{TI}>30 \%)$, and $\mathrm{C}$ - moderate carbon and trade intensities $(5 \%<\mathrm{CI} \leq 30 \% \cap 10 \%<\mathrm{TI} \leq 30 \%)$. Figure 1 plots the location of 3-digit sectors in a diagram with $\mathrm{CI}$ on the vertical and TI on the horizontal axis. $^{8}$ It is evident that category B contains most of the sectors the EC considers at risk of carbon leakage, and that most of these sectors are not carbon intensive at all (i.e. $\mathrm{CI}<5 \%$ ). We thus split category B according to its carbon intensity and plot in Figure 2 the relative size of the resulting five categories in terms of the shares in the number of firms, in employment and in $\mathrm{CO}_{2}$ emissions. ${ }^{9}$ By all these measures, category B turns out to be the largest group of exempted firms. The share of $\mathrm{CO}_{2}$ emissions that is not exempt from auctioning is as small as $15 \%$, which is in line with an alternative estimate of $23 \%$ by Juergens et al. (2013). This means that the Carbon Leakage Decision leaves most pollution rights with European industry and hence strongly undermines the principle of full auctioning established in the amended ETS directive. We get back to this issue in Section 5.

\subsection{Related literature}

How do these metrics relate to the profit impact of the EU ETS? On the one hand, previously grandfathered firms will be forced to pay the market price for the right to pollute. The CI measure is based on the assumption that the cost burden is proportional to the ratio of direct and indirect emissions to gross value added.

\footnotetext{
${ }^{8}$ In a critical appraisal of the Carbon Leakage Decision, Clò (2010) presents a similar visualization but does not show the size of sectors for lack of a match to firm-level data.

${ }^{9}$ Figure E. 2 in the Appendix compares the size of these groups across different samples, namely (a) all EU ETS firms in the CITL/ORBIS matched sample, (b) all such firms in the six countries where we interviewed firms, and (c) all EU ETS firms we interviewed. This confirms that our interview sample is representative of the underlying population.
} 
Figure 2: Relative size of the exemption groups

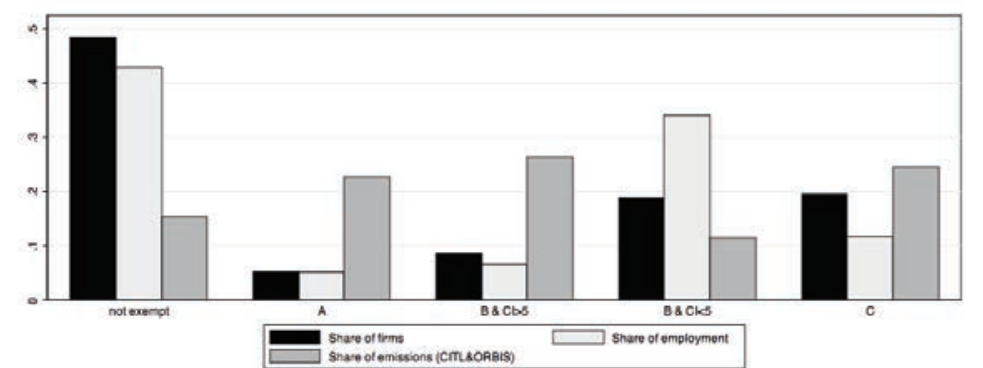

Notes: The chart displays the relative size of each group of NACE industries which are defined by the exemption criteria. Category B (very trade intensive sectors) is subdivided into low and moderate carbon intensity. The sample includes the 4,254 manufacturing firms participating in the EU ETS and matched to ORBIS. The first bar indicates a group's share in the total number of firms, the second bar its share in employment, and the third bar its share in $\mathrm{CO}_{2}$ emissions, based on the number of surrendered permits recorded in the CITL. To compute CI and TI figures at the NACE 4-digit level, we follow the methodology and databases used by the EU Commission (2009).

On the other hand, the demand response conditions a firm's ability to pass on this cost burden to its consumers in the form of higher prices. Doing so will be more difficult for a firm whose customers can easily substitute to relatively cheaper products from competitors located outside the EU. Import penetration is a widely used proxy for cost pass-through. However, the TI metric also contains the export ratio whose relation to the demand response is ambiguous. While the firm might be competing with non-EU firms for customers in its exports destinations, a higher export intensity also reflects the factor specificity of production which tends to mitigate the profit impact of permit auctioning. ${ }^{10}$ In sum, there may be sectors that look vulnerable according to EU criteria although they can easily replace carbon intensive inputs by less carbon intensive ones, or pass-through the cost of permit auctioning in international product markets. ${ }^{11}$

\footnotetext{
${ }^{10}$ For instance, a firm that benefits a lot from country specific factors - e.g. a skilled labor force, natural resource deposits, or externalities from industrial agglomeration - is less likely to relocate in response to full auctioning than a firm that can easily set up shop elsewhere. If factor specificity creates an absolute advantage (think of Swiss watches), TI will be high because of strong exports, not imports.

${ }^{11}$ If aggregation to the sector level lumps together many different products, then domestic firms may be able to pass-through the costs in some product markets that are less competitive due to concentration or product differentiation, in spite of a high import penetration at the sector level (Clò, 2010).
} 
There is little empirical evidence linking the EU criteria to a sector's vulnerability to carbon leakage. A large number of ex-ante studies evaluates the impact of the EU ETS on competitiveness - defined as either production or profitability - using simulation or economic modeling (McKinsey and Ecofys, 2006a; Demailly and Quirion, 2006, 2008). ${ }^{12}$ While they predict a negative impact on production in most manufacturing industries, these studies also show that profitability is not adversely affected under free permit allocation. In fact, grandfathering overcompensates many industries (Smale et al., 2006). An exception to this is primary aluminum production which although not directly regulated under ETS phase I - suffers adverse impacts on production and profitability due to its exposure to higher electricity prices (Reinaud, 2005; McKinsey and Ecofys, 2006a; Smale et al., 2006). Based on this literature, Sato, Grubb, Cust, Chan, Korppoo, and Ceppi (2007a) propose to use trade intensity, carbon intensity and electricity intensity as proxies for the competitiveness impact of the EU ETS.

Survey evidence shows that EU ETS companies are strongly opposed to more permit auctioning after 2012 (McKinsey and Ecofys, 2006b). So far, however, the EU ETS seems to have neither resulted in significant costs, nor induced a fundamental shift in strategy such as relocation or reduction of the workforce (Kenber et al., 2009).

A few ex-post evaluation studies of the competitiveness effects of the EU ETS have been completed to date, chiefly based on the first trading phase. Anger and Oberndorfer (2008) find no significant correlation between the degree of overallocation of German firms and their revenues or employment. Using balance-sheet data from more

\footnotetext{
${ }^{12} \mathrm{~A}$ widespread approach to assessing aggregate leakage effects has been to calibrate computable general equilibrium models that are capable of predicting the consequences of differential carbon pricing across regions. We do not review these models here as they are not informative about individual industries. Models with exogenous technical change predict carbon leakage rates between 5 and $35 \%$ for the Kyoto Protocol commitments (Paltsev, 2001).
} 
than 2,700 European companies for the period between 2005 and 2008, Abrell, Ndoye, and Zachmann (2011) find small negative impact of the EU ETS on employment, but no significant impact on value added or profit margins. Commins, Lyons, Schiffbauer, and Tol (2011) also use balance-sheet data for a large sample of European firms and find that phase I of the EU ETS had a negative effect on productivity and profits, but not on employment. Since treatment status is determined at the sector level, however, these effects are possibly confounded with those of sector-level shocks to the outcome variables. ${ }^{13}$ Going one step further, Bushnell, Chong, and Mansur (2012) argue that some firms and sectors were profiting from regulation, as the stock prices of ETS companies - particularly in carbon- and electricity-intensive industries - fell significantly in response to a precipitous decline in the permit price which occurred in April 2006. In sum, the existing evidence does not suggest that industrial firms on the whole suffered strong adverse impacts when permits were allocated for free in the first years of the EU ETS.

While the existing literature on the competitiveness impact of the EU ETS analyzes intensive-margin adjustments to production, employment and profits, we focus on the extensive-margin impact. The compensation scheme we propose aims at preventing carbon leakage, following the EC's official justification for those transfers. It differs from the scheme used in a related literature concerned with the welfare costs of industry compensation in general equilibrium (Bovenberg and Goulder, 2002; Bovenberg et al., 2005, 2008). Not least, our paper adds to a rapidly growing literature linking firm-level data on management practices obtained in large-scale, cross-country surveys to official performance data in order to better explain firm-level productivity, energy efficiency and organizational structure (Bloom and van Reenen, 2007; Bloom, Genakos,

\footnotetext{
${ }^{13}$ In addition, none of these studies addresses a possible selection issue at the sector level.
} 
Martin, and Sadun, 2010a; Martin, Muûls, De Preux, and Wagner, 2012b).

\section{Data}

This paper combines three principal sources of data into a unique firm-level data set suitable for analyzing the link between permit allocation and carbon leakage. First, we collect data on vulnerability to carbon pricing - as well as on management practices relating to climate policy more generally - by interviewing managers of manufacturing firms in six European countries: Belgium, France, Germany, Hungary, Poland and the UK. ${ }^{14}$ Second, we augment this information with "hard" data on economic performance from the ORBIS database maintained by Bureau Van Dijk. Third, we obtain data on $\mathrm{CO}_{2}$ emissions from the official EU ETS registry, known as the Community Independent Transactions Log (CITL). Additional EU data sources are used to calculate carbon emissions, $\mathrm{CI}$ and $\mathrm{TI}$ at the sector level. This section describes the data collection and matching processes and summarizes our core data set.

\subsection{Interview based measure of vulnerability to carbon leakage}

To obtain a measure of the expected impact of future climate policies on outsourcing and relocation decisions, we asked managers:

"Do you expect that government efforts to put a price on carbon emissions

will force you to outsource part of the production of this business site in the foreseeable future, or to close down completely?"15

\footnotetext{
${ }^{14}$ Scheduling of interviews began in late August 2009 and the last interview was given in early November 2009.

${ }^{15}$ See Appendix $\mathrm{G}$ for the exact wording and sequencing of the relocation questions. The analysts scoring the responses were instructed to spot obvious inconsistencies and mend them on the fly. For in-
} 
Figure 3: Average vulnerability score by country and industry

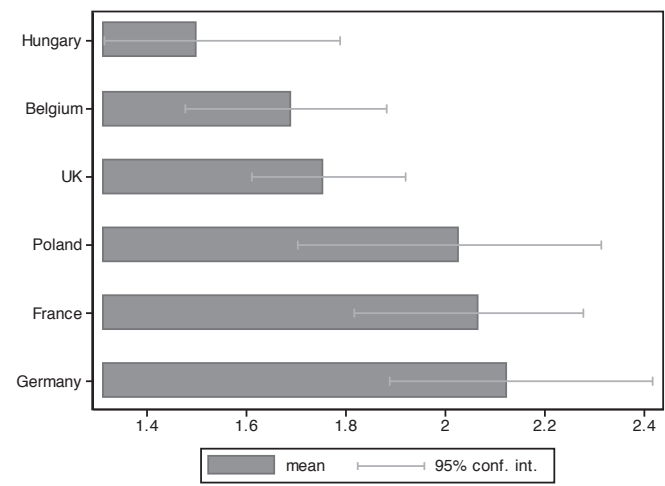

(a) by country

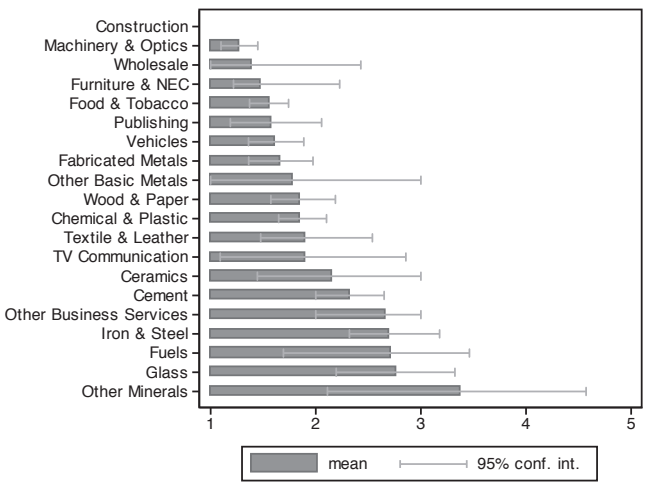

(b) by sector

Notes: The bars show the average score in a given country (a) or 3-digit sector (b). Bootstrapped confidence bands are calculated at the $95 \%$ level. NEC: Not elsewhere classified.

The answers to this question were translated into an ordinal 'vulnerability score' (VS) on a scale from 1 to 5 . Analysts were instructed to assign a score of 5 if the manager expected the plant to be closed completely, and a score of 1 if the manager expected no detrimental impacts at all. A score of 3 was given if the manager expected that at least $10 \%$ of production and/or employment would be outsourced in response to future policies. Scores of 2 or 4 were given to account for intermediate responses.

VS across all firms in the sample has a mean of 1.87 and a standard deviation of 1.29. ETS firms expect a significantly higher impact of 2.14 than non-ETS firms (1.49). Inspection of the raw data suggests that carbon pricing will affect German and French and Polish firms more strongly than British, Belgian and Hungarian firms (cf. Figure 3 a). However, in no country does the $95 \%$-confidence band include outsourcing of more than $10 \%$ of production in response to regulation. Looking across different

stance, question 12b) immediately following question 12a) quoted above, explicitly states that managers should assume they have to pay for all allowances, whereas question 12c) describes a different scenario where $80 \%$ of permits are handed out for free. Should a manager have assumed a lower financial burden in answering 12a), the misunderstanding would have been resolved by question $12 \mathrm{~b}$ ). 
industries, fuels and other minerals, glass, iron \& steel are the most vulnerable (cf. Figure $3 b)$. In all other industries, the average VS is rather low. In no industry do we find that plant closure and complete relocation are in the $95 \%$ confidence interval. ${ }^{16}$

Further results (reported in Appendix Table A.5) show that only French firms expect significantly stronger-than-average impacts after controlling for industrial composition and interview noise. ${ }^{17}$ Hence the heterogeneity in the responses is driven mainly by sectoral differences. Again controlling for interview noise, we find that other minerals, glass, iron \& steel, and cement are the most vulnerable industries, irrespective of employment size. Other energy intensive industries such as food \& tobacco, fabricated metals, and vehicles are significantly less vulnerable than the average.

\subsection{Validity of the vulnerability score}

Given the importance of the VS measure for the analysis to follow, we now describe key aspects of the interview design and the sampling procedure which help to minimize potential sources of bias. Additionally, we present evidence that our measure is internally consistent with other interview results, and that it is externally consistent, based on energy price elasticities of employment in a large sample of firms in Europe and other OECD countries.

Interview design We adopt a survey tool based on structured telephone interviews pioneered by Bloom and van Reenen (2007) and designed to avoid several sources of bias common in conventional surveys (Bertrand and Mullainathan, 2001). Unlike other survey formats, the interviewer engaged the interviewee in a dialog with specific

\footnotetext{
${ }^{16}$ Figure A.1 in the Appendix shows the full distribution of the vulnerability score, by country and industry. Summary statistics are reported in Table A.4.

${ }^{17}$ The set of interview noise controls is described in Section 5 below.
} 
questions for discussion. On the basis of this dialog, the interviewer then assessed the company along various aspects of management relevant for climate policy, including VS. We provided exemplary responses that interviewers could consult when in doubt about giving a high versus a medium or low score for the relevant dimension. The goal was to benchmark the practices of firms according to common criteria. For instance, rather than asking the manager for a subjective assessment of the management's awareness of climate change issues we gauged this by how formal and far-reaching the discussion of climate change topics was in current management.

As in Bloom and van Reenen (2007), the interview process was "double blind". Interviewees were not told that their answers would be scored, so as to avoid giving them an incentive to provide biased information. Conversely, interviewers were given no information about the firm except the contact details, ${ }^{18}$ so as to minimize the chance that the interviewer's preconceptions about the firm could influence the scoring process (Bloom and van Reenen, 2010).

For consistency checks of interviewer scoring, a subset of randomly selected interviews were double-scored by a second team member who listened in. In the regression analysis below, we control for possible bias on the part of the interviewers by including interviewer fixed effects. In addition we control for interview noise due to the manager's characteristics - by including the tenure in the company, dummies for gender and professional background (technical or law) - and due to the time of the interview - by including dummies for month, day of week and time of day (am/pm).

Random sampling Our sampling frame comprised all manufacturing firms with more than 50 but less than 5,000 employees contained in ORBIS for the countries un-

\footnotetext{
${ }^{18}$ Given our focus on medium-sized firms, the graduate students conducting the interviews were unlikely to have prior knowledge about the firm they were interviewing.
} 
der study. Out of a total of 44,605 such firms, possible interview partners were drawn at random and contacted via phone until an interview was given or explicitly denied. We oversampled EU ETS firms by drawing firms at random from the EU ETS registry so that between $50 \%$ and $70 \%$ of managers contacted in each country worked at an EU ETS firm. In total, we contacted 1,451 firms in the six countries and interviewed 761 of them (131 firms in Belgium, 140 in France, 138 in Germany, 69 in Hungary, 78 in Poland, and 209 in the UK). Of all firms we interviewed, 446 (57\%) were in the EU ETS. In spite of a relatively high response rate of 53\%, sample selection bias might arise if interviewed firms differ in systematic ways from firms that declined to be interviewed. We compare the principal firm characteristics available in the ORBIS database - turnover, employment and capital - between firms interviewed and not interviewed, conditional on a firm's participation in the EU ETS. These comparisons are reported in Section A.2 of the Appendix and show no statistically significant evidence of sample selection on observable characteristics.

Internal consistency Table 1 shows that VS correlates in expected ways with other interview responses that also capture vulnerability to carbon pricing in some way but may be deemed less subjective. A low VS is strongly associated with a high cost passthrough as well as with a low share of non-EU competitors. Both circumstances enable firms to pass the cost of carbon pricing on to their customers and thus help to protect them against the detrimental effects of carbon pricing. Moreover, we find a strong positive association between VS and a number of management practices relevant for climate change, such as the setting, monitoring and enforcement of targets for energy consumption or GHG emissions, as well as process innovation in areas related to climate change. This is plausible as the firms most adversely affected by carbon pricing 
Table 1: Correlations between vulnerability score and other interview variables

\begin{tabular}{llc}
\hline \hline & \multicolumn{1}{c}{$(1)$} & \multicolumn{1}{c}{$(2)$} \\
& All firms & EU ETS firms \\
\hline Cost pass-through (\%) & $-0.107^{* * *}$ & $-0.109^{*}$ \\
Share of non-EU competitors (\%) & $0.141^{* * *}$ & $0.135^{* *}$ \\
Non-EU competitors & 0.02 & -0.06 \\
Total competitors & 0.02 & -0.14 \\
Share of sales exported to non EU (\%) & -0.08 & -0.03 \\
Customers are other businesses (D) & $0.105^{* * *}$ & $0.166^{* * *}$ \\
Multinational firm (D) & 0.01 & -0.06 \\
CC related products (S) & 0.01 & 0.01 \\
CC related product innovation (S) & -0.02 & -0.04 \\
CC related process innovation (S) & $0.132^{* * *}$ & $0.108^{*}$ \\
Energy monitoring (S) & $0.169 * * *$ & $0.179 * * *$ \\
Greenhouse gas monitoring (S) & $0.168^{* * *}$ & 0.1 \\
Energy consumption targets (S) & $0.074 *$ & 0 \\
Greenhouse gas targets (S) & $0.207 * * *$ & $0.160^{* * *}$ \\
Enforcement of targets (S) & $0.120^{* * *}$ & 0.1 \\
Employment & 0.02 & -0.06 \\
EU ETS firm (D) & $0.623^{* * *}$ & \\
\hline \hline
\end{tabular}

Notes: Coefficients of correlation between the vulnerability score and other interview variables. Variables refer to numbers unless indicated otherwise; D denotes a dummy variable and $\mathrm{S}$ another interview score constructed in a way similar to the vulnerability score. CC stands for "climate change". Results in column 1 are based on the full sample wheras those in column 2 are calculated using only firms in the EU ETS. Asterisks indicate statistical significance at the $10 \%(*), 5 \%(* *)$ and $1 \%(* * *)$ level.

have stronger incentives to monitor and reduce their carbon intensity and permit liability. When the sample is restricted to include only EU ETS firms, similar qualitative findings emerge although the statistical significance on some of the management variables is lower. In sum, these results support the internal consistency of VS as a measure of the firm's vulnerability to carbon pricing.

External consistency If VS is a valid measure of a firm's propensity to outsource jobs in response to higher carbon prices, one would expect that high VS firms respond to higher energy prices in a similar fashion, especially if energy prices in alternative 
locations abroad remain low. ${ }^{19}$ To test this hypothesis, we regress manufacturing employment on the difference between energy prices at home and abroad, using more than 460,000 firm-year observations from ORBIS. ${ }^{20}$ The energy price differential is calculated at the sector level by subtracting the inverse-distance weighted mean of energy prices abroad from the domestic energy price. To control for differences in labor costs we also include the wage differential, calculated in the same fashion. Factor price differentials are calculated as log differences and vary at the industry, country and year levels. We interact these price variables with different transformations of the VS variable to test for heterogeneous employment responses to changing energy prices. Our regression model allows for firm fixed effects, a full set of country-year effects, and sectoral trends. This controls for unobserved heterogeneity across firms, for transitory shocks at the macro level, and for differences in employment trends across sectors, respectively. We implement this regression using the dynamic panel estimator by Blundell and Bond (1998), which controls for endogenous prices and serially correlated error terms. Section B.1 in the Appendix describes the data and methods used in detail.

Table 2 reports the elasticity estimates based on data for the years 2001 through 2007, separately for a sample of 20 OECD countries and a sample of 16 European countries. We interact the price variables (i) with a dummy indicating whether a firm belongs to a sector with above-median VS (High VS), or (ii) with the deviation of the sector VS from the overall VS mean. In each case, we find strong evidence that the employment response to an increase in the energy price differential decreases with the

\footnotetext{
${ }^{19}$ Following common practice in empirical economics, we use the energy price as a proxy where carbon price data are not available for lack of relevant policies (e.g. Popp, 2002).

${ }^{20}$ Estimating the elasticity in this way abstracts from substitution effects that occur when both home and foreign energy prices change by the same amount. In fact, the domestic energy price should matter for relocation only if energy prices in alternative locations are lower.
} 
Table 2: Estimates of the energy-price elasticity of employment in vulnerable sectors

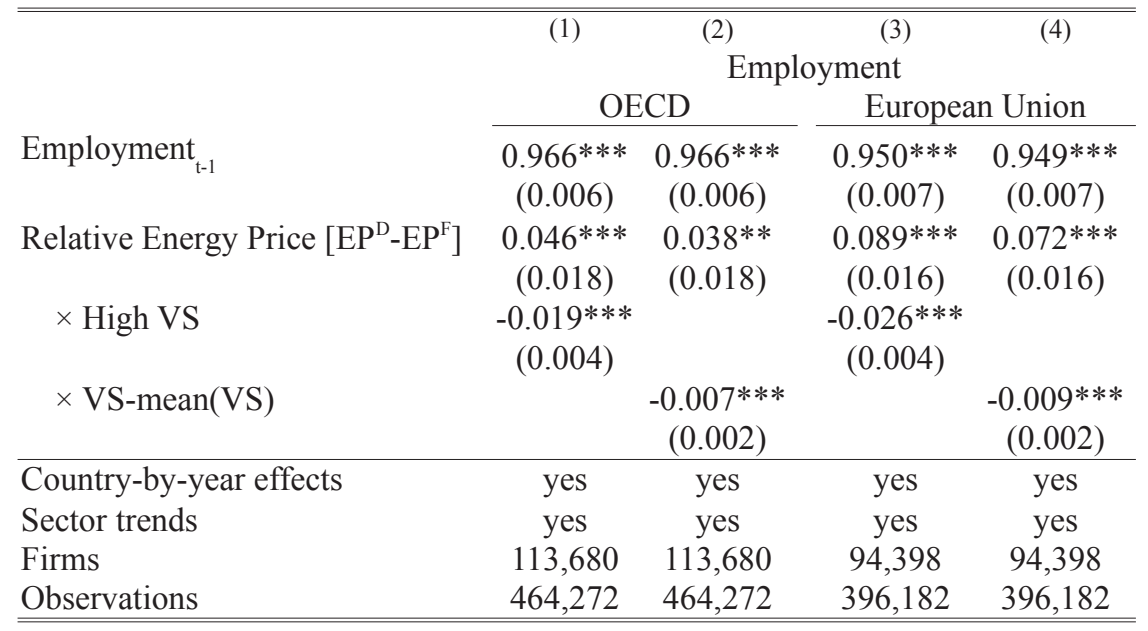

Notes: The dependent variable is firm-level employment measured on a logarithmic scale. The domestic EP index is calculated as the average price across different fuel types (in logs), with constant expenditure weights. The foreign EP is the average EP in all foreign countries, inversely weighted by the geographical distance to that country. The vulnerability score (VS) is the sectoral employment-weighted firm-level VS. High VS indicates a VS above the median. The regressions also include a full set of country-year effects and sectoral trends. The sample comprises all ORBIS firms that reported 10 or more employees at least once between 1999 and 2007. The OECD sample comprises 20 OECD countries (listed in Appendix B.1). In columns 3 and 4, non-EU countries are excluded from the sample and Romania is included. All regressions are implemented with the System GMM by Blundell and Bond (1998). Robust standard errors, clustered at the firm level, are in parentheses. Asterisks indicate statistical significance at the $10 \%(*), 5 \%(* *)$ and $1 \%(* * *)$ levels.

sector's VS. For instance, column 1 reports a small positive energy price elasticity of 0.046 for sectors with below-median VS values. ${ }^{21}$ For "High VS" sectors this elasticity is 0.019 lower. Similarly, column 2 reports that firms in sectors whose VS is 1 score point above the overall mean exhibit an energy price elasticity that is 0.007 lower than the average. The results in columns 3 and 4 are very similar. In sum, these regressions show that the VS - which indicates a higher chance of downsizing domestic operations in response to higher carbon prices - is consistent with how manufacturing firms in Europe and in the OECD adjust their labor input in response to the energy price differential between domestic and foreign locations.

\footnotetext{
${ }^{21}$ That is, a doubling of the energy price differential leads to a 4.6 percent increase in employment. Note that we have no priors about the absolute sign of the elasticity. The net impact on employment depends on the relative size of a substitution effect (positive) and an output effect (negative).
} 
Expectations about free allocation The question underlying VS was asked within the hypothetical policy context of firms not receiving any free permits. This is a counterfactual scenario, not just because manufacturing firms had been receiving free permits throughout the first two phases of the EU ETS, but also because many of them could expect to receive free permits to cover a non-negligible share of their emissions even in Phase III. If respondents anchored their answers to the expected allocation of free permits, rather than to the hypothetical scenario we described to them, this would likely induce downward bias in the VS.

Directive 2009/29/EC specifying the criteria and thresholds for free allocation to sectors at risk of carbon leakage was published four months before we started the interviews. Therefore, we cannot rule out the possibility that some respondents correctly anticipated that they would receive free permits. ${ }^{22}$ If - in spite of our request to consider the case of no free permits - this expectation had a systematic effect on responses, then we should observe a discrete jump in VS around the thresholds. We examine this using a regression discontinuity design that accommodates multiple assignment variables. For a variety of specifications and functional forms, the effect of thresholds on VS is not significant. We thus cannot reject the hypothesis that the available information on free permit allocation did not influence the responses to the hypothetical question underlying VS. ${ }^{23}$ A detailed description of this analysis is relegated to Ap-

\footnotetext{
${ }^{22}$ It seems unlikely that firms could predict with certainty whether or not they would be exempt from permit auctions, because the carbon leakage thresholds applied to EU wide sector averages of carbon and trade intensities. The data requirements for computing these averages are not trivial (Juergens et al., 2013; EU Commission, 2009), and the first official list of sectors at risk was not published until after the interview process was completed, cf. Decision 2010/2/EU of 24 December 2009.

${ }^{23}$ Given this result, it seems unlikely that firms not at risk of carbon leakage would underreport their vulnerability due to the prospect of free allowances under the benchmarking rules. Free allocations to those firms will be as small as $30 \%$ of benchmark emissions in 2020. Moreover, the Benchmark Decision was published in May 2011, i.e. 18 months after the completion of the interviews. This means that the political uncertainty these firms faced about how many free allowances they would get was much larger than for the sectors covered by the Carbon Leakage Decision.
} 
Table 3: Firm characteristics

\begin{tabular}{lrrrrrr}
\hline \hline & Mean & $\begin{array}{c}\text { Standard } \\
\text { deviation }\end{array}$ & $10^{\text {th }}$ & $\begin{array}{c}\text { Percentiles } \\
50^{\text {th }}\end{array}$ & $90^{\text {th }}$ & Obs. \\
\hline Firm & & & & & & \\
$\quad$ Age (years) & 37 & 37 & 7 & 22 & 87 & 736 \\
Turnover (EUR million) & 477.69 & $2,790.11$ & 9.79 & 77.20 & 728.37 & 696 \\
Number of employees & 1,004 & 3,891 & 84 & 298 & 1,890 & 699 \\
EBIT (EUR million) & 17.18 & 78.25 & -1.85 & 2.31 & 41.65 & 683 \\
Number of shareholders & 2 & 5 & 1 & 1 & 3 & 761 \\
Number of subsidiaries & 4 & 24 & 0 & 1 & 8 & 761 \\
Firm's Global Ultimate Owner & & & & & & \\
$\quad$ Turnover (USD million) & 23,800 & 54,100 & 176 & 5,948 & 57,500 & 241 \\
Number of employees & 46,804 & 72,634 & 492 & 15,211 & 107,299 & 226 \\
\hline \hline
\end{tabular}

Notes: EBIT: Earnings Before Interests and Taxes. Interview data sample of 761 firms. Figures correspond to the year 2007. Source: ORBIS (Bureau Van Dijk).

pendix B.2.

\subsection{Data on economic performance and carbon emissions}

Balance-sheet data on firm performance and other characteristics are obtained from ORBIS. Table 3 summarizes selected variables for the sample of 761 firms we interviewed. The sample is well stratified with respect to age, size, profitability, and ownership. Table A.3 in the Appendix compares the sample means of each characteristic between firms in the EU ETS with those that are not and reports the results from a test of equality group means. This reveals that EU ETS firms are older, larger and more profitable than their counterparts outside the EU ETS, and that these differences are statistically significant.

Data on carbon emissions and permit allocations for all EU ETS firms in the sample are calculated as the average, respectively, of verified emissions and allocated permits between 2005 and 2008 obtained from CITL. Benchmark allocations for phase III are taken from the National Implementation Measures (NIMs). We aggregate these 
installation-level variables up to the firm level before matching them to ORBIS.

EU ETS firms interviewed by us are sampled either from ORBIS or from the CITL. They are subsequently matched to the CITL or ORBIS, by hand (in the case of Germany, Hungary and the UK) or using lookup tables available in the public domain (in the case of France, Belgium and Poland). This also allows us to assign firms in the CITL to 4-digit NACE industrial sectors. ${ }^{24}$ To match firms and countries that are not included in our interviews or in official lookup tables, we draw on a mapping from CITL to ORBIS by Calel and Dechezleprêtre (2012a). ${ }^{25}$ This allows us to match $75 \%$ of CITL installations and emissions to ORBIS firms. NACE rev 1.1 classification and employment data is available for 4,254 firms, $71 \%$ of which are manufacturing firms. Table E.1 of the Appendix summarizes the correspondence between sectoral classifications.

\section{Optimal permit allocation}

In a cap-and-trade scheme, the permit price is determined by the total cap and the marginal cost schedules of all regulated firms. Therefore, the way in which the total cap is allocated across firms should have no bearing on marginal production decisions. However, permit allocation directly affects firm behavior at the extensive margin through its impact on firm profits, because a firm that exits or relocates loses its permit endowment. ${ }^{26}$ This section develops a simple normative model of permit allocation

\footnotetext{
${ }^{24}$ NACE stands for "Nomenclature statistique des activités économiques dans la Communauté européene" (Statistical Classification of Economic Activities in the European Community).

${ }^{25}$ We thank Rafael Calel and Antoine Dechezleprêtre for graciously providing us with NACE code identifiers and employment data based on their mapping. The match comprises 5,037 firms $(9,061$ installations) with a total of 1,743 million tons of $\mathrm{CO}_{2}$.

${ }^{26}$ Since the capacity based updating in phase III does not affect short-run production choices (cf. Section 2.1 above), we choose to model free permit allocation to existing firms as a lump-sum transfer.
} 
where the government's principal concern is to prevent the relocation of production to places where carbon regulation is less stringent.

\subsection{Model setup}

We consider a firm $i$ that is located in a regulated country and earns a profit of $\pi_{i}\left(p, q_{i}\right)$ which depends on the number of free permits $q_{i}$ allocated to the firm and on the prevailing permit price $p$. Since free permits can be regarded as a lump-sum subsidy to the firm we assume that $\frac{\partial \pi_{i}\left(p, q_{i}\right)}{\partial q_{i}}>0 \forall p>0$. By relocating to an unregulated country $f$, firm $i$ would obtain profit $\pi_{i f}$ and incur relocation cost $\kappa_{i}$. The firm relocates if $\pi_{i}\left(p, q_{i}\right)<\pi_{i f}-\kappa_{i}$. We assume that the government has accurate information on the firm's profits at home but cannot observe the net cost of relocation $\varepsilon_{i} \equiv \kappa_{i}-\pi_{i f}$. The government only knows that $\varepsilon_{i}$ is an iid random variable with mean $\mu_{\varepsilon}$ and standard deviation $\sigma_{\varepsilon}$ and that it follows a continuously differentiable distribution function $\Phi_{i}(\cdot)$. Given the binary relocation variable

$$
y_{i} \equiv \mathbf{1}\left\{\varepsilon_{i}<-\pi_{i}\left(p, q_{i}\right)\right\}
$$

the government's assessment of the probability that firm $i$ relocates is thus given by $\operatorname{Pr}\left(y_{i}=1 \mid p, q_{i}\right)=\Phi_{i}\left[-\pi_{i}\left(p, q_{i}\right)\right]$.

The revised Emissions Trading Directive 2009/29/EC grants compensation to polluting industries both to protect their international competitiveness and to prevent carbon leakage. We formalize these policy objectives by assuming that the government minimizes the total expected damage of relocation, expressed in terms of carbon leakage or jobs lost. For brevity, we refer to the objective as 'relocation risk', or use the We explore the implications of output-based updating in Appendix D. 
terms 'carbon leakage risk' or 'job risk' whenever the damage is specified.

The contribution to aggregate relocation risk by individual firm $i$ is given by

$$
r_{i}\left(q_{i}\right)=\Phi_{i}\left[-\pi_{i}\left(p, q_{i}\right)\right] \cdot\left[\alpha l_{i}(p)+(1-\alpha) e_{i}(p)\right]
$$

where $l_{i}(p)$ and $e_{i}(p)$ denote the level of employment and emissions at firm $i$ at permit price $p$, respectively, and $\alpha$ their relative weight in the government's damage assessment. Thus, it is assumed that, when firm i relocates to a non-EU country, all of its jobs are lost and all of its emissions "leak" to non-regulated countries. In what follows, we take the total cap $\bar{Q}$ to be exogenously fixed. Therefore, the carbon price is constant and will be omitted hereafter for ease of notation. ${ }^{27}$

The government chooses how many permits $q_{i}$ to allocate to each firm $i$ so as to minimize aggregate relocation risk $R=\sum_{i=1}^{n} r_{i}\left(q_{i}\right)$ subject to the sum of allocated permits not exceeding the overall cap $\bar{Q}$ :

$$
\min _{\left\{q_{i} \geq 0\right\}} \sum_{i=1}^{n} r_{i}\left(q_{i}\right) \text { s.t. } \sum_{i} q_{i} \leq \bar{Q}
$$

Given the assumptions on $\Phi_{i}$, an additional free permit always brings about a marginal reduction in the probability of relocation. Hence the shadow price $\lambda$ of a permit is positive and the permit constraint holds with equality. The first-order condition for an interior solution is given by

$$
\Phi_{i}^{\prime}\left[-\pi_{i}\left(q_{i}\right)\right] \frac{\partial \pi_{i}\left(q_{i}\right)}{\partial q_{i}}\left[\alpha l_{i}+(1-\alpha) e_{i}\right]=\lambda \quad \forall i
$$

\footnotetext{
${ }^{27}$ The carbon price could vary as the overall distribution of abatement costs changes when some facilities exit. Since our primary concern is with the elasticity of profits w.r.t. free permit allocation, we leave this as a topic for future research.
} 
Equation (5) requires the regulator to equalize, for each firm, the reduction in expected job losses and carbon leakage brought about by the last free permit allocated to that firm.

To appreciate the emphasis on the marginal relocation probability, consider two firms with identical levels of employment and abatement at price $p^{c}$ but with different relocation probabilities. Optimality requires that the government allocate the bulk of free permits not to the firm with the highest relocation propensity but rather to the firm where these permits bring about the largest reduction in the relocation probability, weighted by a convex combination of jobs and emissions at the firm. Although this important insight follows immediately from straightforward economic reasoning, it has not been voiced in the public debate on free permit allocation so far.

Consider now the dual of program (4) which seeks to minimize the amount of free permits allocated to the firms subject to the constraint that relocation risk does not exceed the level $\bar{R}$ :

$$
\min _{q_{i} \geq 0} \sum_{i=1}^{n} q_{i} \text { s.t. } \sum_{i=1}^{n} r_{i}\left(q_{i}\right) \leq \bar{R}
$$

It is easily seen that the first-order condition for an interior solution to this program requires that the impact on relocation risk of the last free permit be equal across all firms receiving positive amounts of permits, as was shown above for the primal program.

\subsection{Numerical solution}

In solving for the optimal permit allocation we want to allow for firm-specific relocation probability functions $\Phi_{i}(\cdot)$ and for corner solutions that can arise when the marginal impact of the first permit on relocation risk at a firm falls short of its shadow value. This suggests a numerical approach to solving programs (4) and (6) based on 
standard dynamic programming techniques. ${ }^{28}$

For an arbitrary ordering of firms, the recursive formulation of program (4) yields the Bellman equation

$$
V_{i}\left(s_{i}\right)=\min _{0 \leq q_{i} \leq s_{i}} \Phi_{i}\left[-\pi_{i}\left(q_{i}\right)\right]\left[\alpha l_{i}+(1-\alpha) e_{i}\right]+V_{i+1}\left(s_{i}-q_{i}\right)
$$

where $s_{i}$ is the amount of total permits left when reaching firm $i$ and $V_{i+1}\left(s_{i}-q_{i}\right)$ is the value of leaving $s_{i}-q_{i}$ permits to all remaining firms in the sequence. It is straightforward to solve eq. (7) numerically, starting with the last firm $N$ in the sequence whose value function is given by $V_{N}\left(s_{N}\right)=\Phi_{i}\left[-\pi_{N}\left(s_{N}\right)\right]\left[\alpha l_{N}+(1-\alpha) e_{N}\right]$. For firms earlier in the sequence, we iterate on (7) to choose the optimal $q_{i}$ for each possible $s_{i}$. The same approach allows us to solve the dual problem (6) after inverting eq. (3) to get $q_{i}=\pi_{i}^{-1}\left[-\Phi_{i}^{-1}\left(\frac{r_{i}}{\alpha l_{i}+(1-\alpha) e_{i}}\right)\right]$. Rather than allocating the pieces of a fixed pie of free permits so as to reduce total risk, we now allocate the pieces of a fixed pie of relocation risk so as to minimize total permits. The analogue to Bellman equation (7) is given by

$$
W_{i}\left(s_{i}\right)=\min _{0 \leq r_{i} \leq s_{i}} \pi_{i}^{-1}\left[-\Phi_{i}^{-1}\left(\frac{r_{i}}{\alpha l_{i}+(1-\alpha) e_{i}}\right)\right]+W_{i+1}\left(s_{i}-r_{i}\right)
$$

and can be solved recursively in the same fashion as described above.

Calculating the marginal propensity to relocate We assume that the unobserved net cost of relocation follows a logistic distribution and consider a linear approximation

\footnotetext{
${ }^{28}$ Appendix C provides further information on the computational details.
} 
to the profit function $\pi_{i}\left(q_{i}\right)=\delta_{0 i}+\delta_{1 i} q_{i}{ }^{29}$ This yields the relocation probability

$$
\operatorname{Pr}\left(y_{i}=1 \mid q_{i}\right)=\Phi_{i}\left(-\pi_{i}\left(q_{i}\right)\right)=\frac{1}{1+\exp \left(\beta_{0 i}+\beta_{1 i} q_{i}\right)}
$$

with parameters $\beta_{0 i} \equiv \frac{\delta_{i 0}+\mu_{\varepsilon}}{\sigma_{\varepsilon}}$ and $\beta_{1 i} \equiv \frac{\delta_{1 i}}{\sigma_{\varepsilon}}$. We calibrate these parameters for each firm based on the interview responses. While the VS captures the managers' assessment of the future impact of carbon pricing on their businesses under the assumption of no free allocation, we obtain its gradient by asking how the VS would change if the company was granted permits for $80 \%$ of its emissions at no cost. ${ }^{30}$ For a given mapping from the VS into relocation probabilities, ${ }^{31}$ this allows us to evaluate the relocation probability with no free permits, $\operatorname{Pr}_{i}\left(y_{i}=1 \mid q_{i}=0\right)$ as well as with $80 \%$ free permits $\operatorname{Pr}_{i}\left(y_{i}=1 \mid q_{i}=0.8 e_{i}\right)$ and use these to back out the parameters $\beta_{0 i}=\ln \left[\frac{1-\operatorname{Pr}_{i}\left(y_{i}=1 \mid q_{i}=0\right)}{\operatorname{Pr}_{i}\left(y_{i}=1 \mid q_{i}=0\right)}\right]$ and $\beta_{1 i}=\frac{1}{0.8 e_{i}} \ln \left[\frac{1-\operatorname{Pr}_{i}\left(y_{i}=1 \mid q_{i}=0.8 e_{i}\right)}{\operatorname{Pr}_{i}\left(y_{i}=1 \mid q_{i}=0.8 e_{i}\right)}-\beta_{0 i}\right]$ in equation (9).

\subsection{Simulation of counterfactual allocations}

We compute optimal allocations under different assumptions about the government's objective function (risk vs. cost minimization), about the damage weights (job loss vs. carbon leakage ), and about the level at which free permits are allocated (firm or sector). Counterfactual permit allocations provide a benchmark against which to compare de facto permit allocations in phase II (grandfathering) and phase III (benchmarking),

\footnotetext{
${ }^{29}$ We allow the coefficient on free permits to vary across firms to account for the fact that the present value of free permits allocated during phase III varies across firms. This reflects differences in capital costs due to risk, taxation, and access to credit.

${ }^{30}$ This corresponds to questions $12 \mathrm{a}$ and $12 \mathrm{c}$ of the interview, cf. Appendix G. Figure E.1 in Appendix $\mathrm{C}$ shows the distribution of the change in vulnerability conditional on the initial VS.

${ }^{31}$ We follow the interview scoring grid in assigning probabilities of $0.01,0.10$ and 0.99 to scores 1,3 and 5 , respectively. We interpolate between these numbers and assign probabilities of 0.05 and 0.55 to scores 2 and 4, respectively.
} 
so as to quantify the efficiency costs of these allocations.

Minimizing relocation risk Table 4 compares the relocation risk associated with the free permits handed out under grandfathering or benchmarking (in column 1) with the minimal risk, subject to the constraint that the total number of free permits matches the amount handed out in the reference scenario (in column 2). The first row shows that job risk under grandfathering can be reduced from $4.2 \%$ to $2.9 \%$ of employment in EU ETS sectors when permits are allocated optimally across firms. With benchmarking, job risk increases by two thirds to $6.9 \%$ of ETS employment. Optimal redistribution of permits to firms brings the risk back down to $2.9 \%$. To account for sampling error surrounding these point estimates, we report the bootstrapped 95th percentile of each statistic in brackets. This shows that the risk to jobs amounts to at most $4.7 \%$ of ETS employment in 95 out of 100 cases. Moreover, while the average reduction in job risk compared to the benchmarking scenario is almost 4 percentage points, a reduction by at least 1.9 percentage points can be achieved with $95 \%$ probability.

Panel B of Table 4 reports the risk of carbon leakage as a share of total emissions covered by the ETS for the same allocations. The baseline risk, which at $15.7 \%$ is higher than the job risk, increases by almost half to $22.8 \%$ under benchmarking. Efficient allocation reduces the leakage risk to just above $13 \%$ for either permit constraint. When benchmarking is taken as the reference scenario, optimal permit allocation reduces the average leakage risk by 9.6 percentage points. Accounting for sampling error, the risk reduction is at least 4.5 percentage points with $95 \%$ probability.

Furthermore, we calculate minimal relocation risk under the additional constraint that the government cannot assign free permits at the firm level but only at the sector level. This is meant to take into account political constraints that led the EC to establish 
Table 4: Risk of job loss and carbon leakage

\begin{tabular}{|c|c|c|c|c|c|}
\hline Reference scenario & $(1)$ & $\begin{array}{c}(2) \\
\text { Minimi }\end{array}$ & (3) & (4) & $\begin{array}{c}\text { (5) } \\
\text { in Risk }\end{array}$ \\
\hline \multicolumn{6}{|c|}{ A. Percentage share of ETS employment at risk } \\
\hline Grandfathering & 4.16 & $\begin{array}{c}2.93 \\
{[4.66]}\end{array}$ & $\begin{array}{c}3.23 \\
{[5.03]}\end{array}$ & $\begin{array}{c}-1.23 \\
{[-0.56]}\end{array}$ & $\begin{array}{c}-0.93 \\
{[-0.37]}\end{array}$ \\
\hline Benchmarking & 6.92 & $\begin{array}{c}2.94 \\
{[4.66]}\end{array}$ & $\begin{array}{c}4.51 \\
{[6.54]}\end{array}$ & $\begin{array}{c}-3.98 \\
{[-1.92]}\end{array}$ & $\begin{array}{c}-2.41 \\
{[-0.46]}\end{array}$ \\
\hline \multicolumn{6}{|c|}{ B. Percentage share of ETS emissions at risk } \\
\hline Grandfathering & 15.66 & $\begin{array}{c}13.15 \\
{[23.88]}\end{array}$ & $\begin{array}{c}14.34 \\
{[24.16]}\end{array}$ & $\begin{array}{c}-2.51 \\
{[-0.36]}\end{array}$ & $\begin{array}{c}-1.32 \\
{[-0.22]}\end{array}$ \\
\hline Benchmarking & 22.79 & $\begin{array}{c}13.20 \\
{[23.89]}\end{array}$ & $\begin{array}{c}21.91 \\
{[31.80]}\end{array}$ & $\begin{array}{c}-9.59 \\
{[-4.45]}\end{array}$ & $\begin{array}{c}-0.88 \\
{[3.18]}\end{array}$ \\
\hline Optimized over & - & Firms & Sectors & Firms & Sectors \\
\hline
\end{tabular}

Notes: Shares of jobs (panel A) or $\mathrm{CO}_{2}$ emissions (panel B) at risk of relocation are expressed relative to total employment or emissions at all ETS firms in the sample. Column 1 reports actual risk associated with a given reference scenario (grandfathering or benchmarking) whereas columns 2 and 3 report minimal risk subject to the constraint that the total number of free permits not exceed the amount allocated under the reference scenario. Permit allocation is optimized across firms (column 2) or across sectors (column 3). Columns 4 and 5 report the change in risk after optimization. In addition to the point estimates, columns 2 through 5 report the 95 th percentiles in brackets, obtained from a non-parametric bootstrap with resampling.

exemption criteria at the 4-digit sector level. We assume that a firm receives permits according to its share in the sector's total emissions under grandfathering and aggregate the resulting relocation risk across firms within sectors. The results in columns 3 and 5 of Table 4 show that both job and leakage risks are higher than with firm-level allocations. ${ }^{32}$ While sector-level allocation still reduces job risk compared to benchmarking - at least 0.5 percentage points with $95 \%$ probability, and 2.4 percentage points on average - this is not guaranteed anymore for $\mathrm{CO}_{2}$ risk. In fact, the 95th percentile of the risk change reported in column 5 is positive. Unlike grandfathering, benchmarking sometimes leads to lower leakage risk than optimal sector-level allocations. These efficiency gains can be attributed to the within-sector allocation of permits and partly

\footnotetext{
${ }^{32}$ The constraints on the number of free permits are binding now because grandfathering individual firms with a high marginal impact of free permits is more costly under sector-level allocation as all other firms in the sector must be given free permits as well. Clearly, those permits are then not available anymore to grandfather more vulnerable firms in other sectors.
} 
Table 5: Permits allocated for free (in $\%$ of total emissions)

\begin{tabular}{|c|c|c|c|}
\hline Scenario & $\begin{array}{c}\text { (1) } \\
\text { Actual }\end{array}$ & \multicolumn{2}{|c|}{ Minimized Allocation } \\
\hline Grandfathering & 100.0 & $\begin{array}{c}14.3 \\
{[31.4]}\end{array}$ & $\begin{array}{c}24.5 \\
{[39.2]}\end{array}$ \\
\hline Benchmarking & 52.3 & $\begin{array}{c}1.6 \\
{[7.0]}\end{array}$ & $\begin{array}{c}13.0 \\
{[22.3]}\end{array}$ \\
\hline Risk constraint & - & Jobs & $\mathrm{CO}_{2}$ \\
\hline
\end{tabular}

Notes: Column 1 reports the share of free permits in total emissions under different scenarios. Minimal permit allocations are calculated subject to the constraint that the total relocation risk not exceed the one under the scenario considered, where relocation risk is measured in terms of either job loss $(\alpha=1)$ or $\mathrm{CO}_{2}$ emissions leakage $(\alpha=0)$. The 95th percentile of the permit share, obtained from a non-parametric bootstrap with resampling, is reported in brackets.

justify the considerable administrative effort that went into benchmarking.

Cost minimization Minimizing the amount of free permits subject to a given relocation risk can be regarded as the tax payer's cost minimization program because it minimizes the amount of foregone auction revenue for a given outcome. Table 5 displays the share of permits handed out for free under different allocation schemes. The first row shows that optimal allocation at the firm level gives rise to drastic efficiency gains. The relocation risk associated with grandfathering could be achieved by handing out only between $14.3 \%$ and $24.5 \%$ of permits for free, depending on whether job risk or carbon leakage risk is held fixed. ${ }^{33}$

Under benchmarking, a large number of sectors and particularly the carbon-intensive ones will continue to be exempt from permit auctioning. As a consequence, $52.3 \%$ of emissions will continue to be allocated for free. This propels the job risk to a very high level that could be achieved by optimally allocating free permits for a mere $1.6 \%$

\footnotetext{
${ }^{33}$ Two mechanisms drive this result. First, the majority of firms in our sample report that their propensity to relocate does not vary with the amount of free permits. It is optimal to assign zero free permits to those firms. Second, among the remaining firms, free permits are allocated in such a way as to equalize the marginal propensity to relocate, weighted by jobs or carbon emissions, as required by the first-order condition (5).
} 
of total emissions. Carbon leakage risk also increases substantially with benchmarking. Obtaining this level of leakage risk at minimal cost would require just under $13 \%$ of permits to be allocated for free. Given that sampling error may affect the point estimates, one can make the more cautious statement that, with $95 \%$ probability, the level of job risk induced by the benchmarking rules could be achieved by allocating at most $7.0 \%$ of the permits for free. The corresponding figure for carbon leakage risk is 22.3\%. This means that EU governments could raise additional revenue by auctioning a much larger amount of emissions permits instead of allocated them free, without increasing the expected cost of carbon leakage or job loss. We shall discuss this further in Section 5.3 below.

\subsection{Feasible optimal permit allocation}

We have shown above that allocating permits optimally will significantly reduce relocation risk compared to the Benchmarking scheme currently in place. Since this approach relies on information that is not publicly observable and easy to manipulate, a possible future survey would need an appropriate mechanism to induce firms to report their vulnerability to carbon pricing truthfully. In this section we take an alternative approach and use the survey information to develop simple allocation rules which are based on easily observable characteristics of firms.

Given a total amount of free permits $\bar{Q}$, an allocation share $\theta_{i}=f\left(x_{i} ; \gamma\right)$ maps a vector $x_{i}=\left(x_{i}^{1}, \ldots, x_{i}^{k}\right)$ of $k$ observable characteristics for firm $i$ into the unit interval. Suppose that the function $f(\cdot)$ is known up to a parameter vector $\gamma$. Substituting $\hat{q}_{i}=$ 
$\theta_{i} \bar{Q}$ into the risk minimization program (4) yields

$$
\min _{\gamma \in \Gamma} \sum_{i=1}^{n} r_{i}\left(f\left(x_{i} ; \gamma\right) \bar{Q}\right) \text { s.t. } \sum_{i=1}^{n} f\left(x_{i} ; \gamma\right)=1 \wedge f\left(x_{i} ; \gamma\right) \geq 0 \quad \forall i
$$

As this can be seen as a constrained version of (4), we refer to its solution as the "feasible optimal allocation". We specify an allocation rule based on the Cobb-Douglas function, $f\left(x_{i} ; \gamma\right)=\frac{\prod_{k}\left(x_{i}^{k}\right)^{\gamma_{k}}}{\sum_{j=1}^{n} \prod_{k}\left(x_{j}^{k}\right)^{\gamma_{k}}}$, which generalizes e.g. grandfathering of historic emissions $e_{i}$ (that is, $f\left(e_{i} ; \gamma\right)=\frac{e_{i}^{\gamma_{e}}}{\sum_{j} e_{j}^{\gamma_{e}}}$ and $\gamma_{e}=1$ ) to the case of multiple variables. We solve for $\gamma$ using a standard maximum likelihood solver where $r_{i}\left(f\left(x_{i} ; \gamma\right) \bar{Q}\right)$ corresponds to the likelihood contribution of observation $i$.

Table 6 reports the solution vector $\hat{\gamma}$ for $x$-vectors of varying lengths (panel A) along with the associated risk of job loss and carbon leakage (panel B). We hold $\bar{Q}$ fixed at the total amount of permits allocated for free during phase III; i.e. $\bar{Q}=\sum_{i} q_{i}^{b}$, where $q_{i}^{b}$ is the average annual amount of free permits received by firm $i$ under the benchmarking rules. As above, we minimize relocation risk either in terms of jobs or carbon emissions. We start by including only $q_{i}^{b}$ in $x_{i}$, as an alternative way of assessing the efficiency of free allocation in phase III. If $q_{i}^{b}$ is optimal, we should find that $\hat{\gamma}_{b}=1$. If $\gamma_{b}<1$, risk can be reduced by shifting permits from firms that receive more permits to those that receive less, and vice versa if $\gamma_{b}>1$. When minimizing job risk, we obtain a point estimate of $\hat{\gamma}_{b}=0.44$, which is smaller than 1 at the $5 \%$ significance level and corroborates our earlier finding that the benchmarking allocations induce too much job risk. In fact, the feasible optimal allocation reported in column 1 reduces job risk by 1.4 percentage points.

Next, we examine three allocation rules based on different combinations of observable characteristics. For instance, when using historic $\mathrm{CO}_{2}$ emissions and employment 
Table 6: Feasible optimal allocation rules

\begin{tabular}{|c|c|c|c|c|c|c|}
\hline & \multicolumn{4}{|c|}{ Minimizing expected job loss } & \multicolumn{2}{|c|}{$\begin{array}{l}(5) \\
\text { Minimizing expected } \\
\text { carbon leakage }\end{array}$} \\
\hline \multicolumn{7}{|c|}{ A. Parameter estimates $\hat{\gamma}$} \\
\hline $\begin{array}{l}\text { Benchmarking } \\
\text { allocation }\end{array}$ & $\begin{array}{c}0.44 \\
{[0.23,0.94]}\end{array}$ & & & & $\begin{array}{c}1.13 \\
{[0.83,1.27]}\end{array}$ & \\
\hline $\mathrm{CO}_{2}$ emissions & & $\begin{array}{c}0.63 \\
{[0.51,0.85]}\end{array}$ & $\begin{array}{c}0.58 \\
{[0.39,0.78]}\end{array}$ & $\begin{array}{c}0.63 \\
{[0.50,0.82]}\end{array}$ & & $\begin{array}{c}1.02 \\
{[0.85,2.66]}\end{array}$ \\
\hline Employment & & $\begin{array}{c}0.23 \\
{[0.11,0.40]}\end{array}$ & $\begin{array}{c}0.29 \\
{[0.12,0.57]}\end{array}$ & & & $\begin{array}{c}-0.20 \\
{[-0.98,-0.03]}\end{array}$ \\
\hline Turnover & & & & $\begin{array}{c}0.20 \\
{[0.11,0.33]}\end{array}$ & & \\
\hline Carbon intensity & & & $\begin{array}{c}0.21 \\
{[-0.03,0.53]}\end{array}$ & & & \\
\hline $\begin{array}{l}\text { Trade intensity w/ } \\
\text { less developed }\end{array}$ & & & $\begin{array}{c}-0.05 \\
{[-0.11,0.46]}\end{array}$ & & & \\
\hline \multicolumn{7}{|c|}{ B. Minimized risk and change to Benchmarking allocation (in \% of total ETS employment or emissions) } \\
\hline Job risk & $\begin{array}{c}5.54 \\
{[9.05]}\end{array}$ & $\begin{array}{c}4.61 \\
{[7.14]}\end{array}$ & $\begin{array}{c}4.51 \\
{[6.73]}\end{array}$ & $\begin{array}{c}4.58 \\
{[7.29]}\end{array}$ & $\begin{array}{c}8.21 \\
{[12.08]}\end{array}$ & $\begin{array}{c}9.14 \\
{[15.51]}\end{array}$ \\
\hline$\Delta$ & $\begin{array}{l}-1.39 \\
{[-0.09]}\end{array}$ & $\begin{array}{l}-2.31 \\
{[-0.74]}\end{array}$ & $\begin{array}{l}-2.41 \\
{[-0.88]}\end{array}$ & $\begin{array}{l}-2.35 \\
{[-0.73]}\end{array}$ & $\begin{array}{c}1.28 \\
{[2.71]}\end{array}$ & $\begin{array}{c}2.22 \\
{[7.09]}\end{array}$ \\
\hline $\mathrm{CO}_{2}$ risk & $\begin{array}{c}29.66 \\
{[39.53]}\end{array}$ & $\begin{array}{l}26.73 \\
{[37.61]}\end{array}$ & $\begin{array}{l}26.05 \\
{[35.50]}\end{array}$ & $\begin{array}{l}25.43 \\
{[36.14]}\end{array}$ & $\begin{array}{c}22.12 \\
{[32.33]}\end{array}$ & $\begin{array}{c}23.22 \\
{[31.78]}\end{array}$ \\
\hline$\Delta$ & $\begin{array}{c}6.88 \\
{[13.17]}\end{array}$ & $\begin{array}{c}3.94 \\
{[8.86]}\end{array}$ & $\begin{array}{c}3.27 \\
{[8.25]}\end{array}$ & $\begin{array}{c}2.64 \\
{[8.00]}\end{array}$ & $\begin{array}{c}-0.67 \\
{[-0.01]}\end{array}$ & $\begin{array}{c}0.44 \\
{[4.19]}\end{array}$ \\
\hline
\end{tabular}

Notes: The sample consists of all 344 EU ETS firms we interviewed and for which we could match data on the phase III allocation, employment, turnover and $\mathrm{CO}_{2}$ emissions. Panel A reports the parameters of the optimal feasible allocation rule for different vectors of observable variables. Panel B reports the associated risk of employment loss (in \% of employment at all firms in the sample) and leakage (in $\%$ of $\mathrm{CO}_{2}$ at all firms in the sample). The change is computed as the difference between minimal risk and the risk induced by the EU Benchmark Allocation. The optimality criterion is either job loss (columns 1 to 4) or carbon leakage (columns 5 and 6). Carbon intensity and trade intensity with less developed countries (TI less) are defined at the 4-digit industry level. The numbers in brackets report two-sided 95\% confidence intervals of the coefficient estimates in Panel A and the 95th percentiles of the risk statistic in Panel B, obtained from a bootstrap with 100 replications.

size of a firm, the job risk drops by 2.3 percentage points (in column 2). This reduction is significant and closes $58 \%$ of the gap to the unconstrained minimum of $2.9 \%$ of all jobs in EU ETS firms. ${ }^{34}$ Compared to column 1, the additional risk reduction is brought about by considering not only the firm's past $\mathrm{CO}_{2}$ emissions but also employment, albeit with a smaller weight. Adding sector characteristics, such as carbon intensity and trade intensity with less developed countries, to the allocation function

\footnotetext{
${ }^{34}$ Panel B reports a reduction by at least 0.7 percent of EU ETS employment in 95 out of 100 bootstrap replications.
} 
results in a small additional reduction of job risk, although the difference is not statistically significant. ${ }^{35}$ Finally, measuring firm size in terms of turnover rather than employment (in column 4) yields results virtually identical to those in column 2.

Feasible optimal allocation rules for minimizing $\mathrm{CO}_{2}$ risk are reported in columns 5 and 6 . Including only the EU benchmark allocation yields a parameter estimate $\hat{\gamma}_{b}$ which is not significantly different from unity. This is in line with the earlier finding that we cannot significantly reduce risk compared to the benchmark allocation. The same conclusion arises in column 6 where we include firm level employment and $\mathrm{CO}_{2}$ in the allocation function. ${ }^{36}$

Two important lessons emerge from the feasible approach to optimal permit allocation. First, a simple allocation rule based on easily observable firm level variables performs at least as well as the benchmarking allocation, which is based on an elaborate - and presumably much more costly - administrative and political process. Second, feasible allocation rules based on both past emissions and firm size significantly reduce job risk, but have no significant impact on $\mathrm{CO}_{2}$ risk. This suggests that there is scope for consensus between different stakeholders concerned with different types of relocation risk.

\section{The empirical content of carbon leakage criteria}

We have argued that economically efficient industry compensation schemes should be based on marginal relocation risk. In practice, compensation has always been based on absolute relocation risk, which is measured by relatively unsophisticated indicators.

\footnotetext{
${ }^{35}$ We use TI with less developed countries because we find it to be more correlated with the VS than the overall TI used by the Commission, as explained in Section 5 below.

${ }^{36}$ We do not find a significant reduction of $\mathrm{CO}_{2}$ risk when including trade and carbon intensity as in column 3, either. These results are available on request.
} 
Table 7: Vulnerability score and exemption criteria

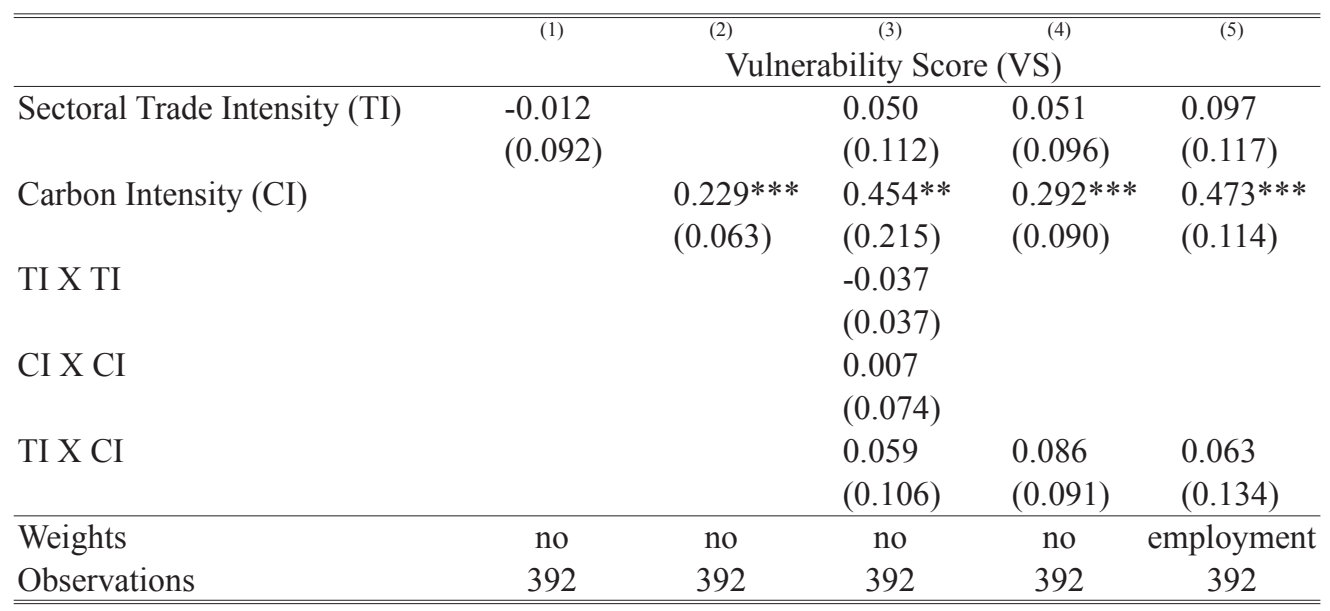

Notes: OLS regressions in columns 1 to 4 and Weighted Least Squares (WLS) regression in column 5. The dataset is a crosssection of 392 interviewed firms that are part of the EU ETS and for which CITL, sectoral trade and carbon intensity data are available. The dependent variable is the vulnerability score of the firm given by the interviews data. In column 5 , the score is weighted by the firm's employment. As explanatory variables, CI indicates carbon intensity and TI trade intensity which are calculated using data from Eurostat and the EU Commission. $\mathrm{X}$ indicates that two variables are interacted. All regressions include a constant, interview noise controls and country dummies (not reported). Robust standard errors, clustered by 4-digit NACE sector, are given in parentheses. Asterisks indicate statistical significance at the $10 \%(*), 5 \%(* *)$ and $1 \%(* * *)$ level.

As explained in Section 2.2, the EU ETS uses CI and TI to determine which sectors are at risk of carbon leakage. Given the landmark character of the EU ETS, the same indicators (or close variants of it) have been adopted in actual and proposed legislation creating at least half a dozen regional carbon trading schemes world wide. ${ }^{37}$ Therefore, it is important to know how accurately these indicators identify the firms and sectors most vulnerable to carbon leakage. The vulnerability score derived from the interview responses lends itself to analyzing this question because it provides a direct measure of what the EC tries to approximate using TI and CI .

\footnotetext{
${ }^{37}$ Emission intensity and trade intensity are used to determine eligibility for compensation in the recently implemented carbon trading schemes in California and Switzerland, in Australia's Carbon Pollution Reduction Scheme and in New Zealand's ETS. The same metrics were proposed for a US wide cap-and-trade scheme under the 2009 Waxman-Markey Bill, and will be applied in a future South Korean ETS (cf. Hood, 2010; www . icapcarbonaction.com).
} 
Table 8: Vulnerability score and exemption categories

\begin{tabular}{|c|c|c|c|c|c|}
\hline \multirow[b]{2}{*}{$\mathrm{CI}>30(\mathrm{~A})$} & (1) & \multicolumn{2}{|c|}{ Vulnerability Score } & \multicolumn{2}{|c|}{$\begin{array}{c}(4) \\
\text { Vulnerability Score }>2\end{array}$} \\
\hline & $\begin{array}{l}1.032 * * * \\
(0.303)\end{array}$ & $\begin{array}{l}1.015^{* * *} \\
(0.312)\end{array}$ & $\begin{array}{l}1.996^{* * * *} \\
(0.523)\end{array}$ & $\begin{array}{l}0.714 * * * \\
(0.242)\end{array}$ & $\begin{array}{l}1.704 * * * \\
(0.448)\end{array}$ \\
\hline $\mathrm{TI}>30 \cap \mathrm{CI}<30(\mathrm{~B})$ & $\begin{array}{l}0.225 \\
(0.258)\end{array}$ & & & & \\
\hline $10<\mathrm{TI}<30 \cap 5<\mathrm{CI}<30(\mathrm{C})$ & $\begin{array}{l}0.122 \\
(0.248)\end{array}$ & $\begin{array}{l}0.139 \\
(0.240)\end{array}$ & $\begin{array}{l}0.358 \\
(0.241)\end{array}$ & $\begin{array}{l}0.105 \\
(0.233)\end{array}$ & $\begin{array}{l}0.271 \\
(0.292)\end{array}$ \\
\hline $\mathrm{B} \cap \mathrm{CI}>5$ & & $\begin{array}{l}0.596^{*} \\
(0.316)\end{array}$ & $\begin{array}{l}1.031 * * * \\
(0.322)\end{array}$ & $\begin{array}{l}0.500 * * \\
(0.252)\end{array}$ & $\begin{array}{l}1.267 * * * \\
(0.417)\end{array}$ \\
\hline $\mathrm{B} \cap \mathrm{CI}<5$ & & $\begin{array}{l}-0.053 \\
(0.243)\end{array}$ & $\begin{array}{l}0.056 \\
(0.329)\end{array}$ & $\begin{array}{l}-0.059 \\
(0.233)\end{array}$ & $\begin{array}{l}0.121 \\
(0.389)\end{array}$ \\
\hline Constant & $\begin{array}{l}1.623 * * * \\
(0.516)\end{array}$ & $\begin{array}{l}1.572 * * * \\
(0.523)\end{array}$ & $\begin{array}{l}1.426 \\
(0.912)\end{array}$ & & \\
\hline Weights & no & no & employment & no & employment \\
\hline Observations & 392 & 392 & 392 & 392 & 392 \\
\hline
\end{tabular}

Notes: OLS regressions in columns 1 and 2, WLS in column 3 and Probit regressions in columns 4 and 5. The dataset is a cross-section of 392 interviewed firms that are part of the EU ETS and for which CITL, sectoral trade and carbon intensity data are available. The dependent variable is the vulnerability score (on a scale of 5) of the firm given by the interviews data in regressions 1 to 3 , and a dummy indicating whether the score is higher than 2 in regressions 4 and 5 . In columns 3 and 5 , the firm's employment is used to weight the regression. CI indicates carbon intensity and TI trade intensity, calculated using data from Eurostat and the EU Commission. Based on these, dummies are constructed to represent belonging to categories A, B and $\mathrm{C}$, as well as $(\mathrm{B} \cap \mathrm{CI}>5)$ and $(\mathrm{B} \cap \mathrm{CI}<5)$. These are used as explanatory variables. Columns 4 and 5 report marginal effects of the probit regressions. All regressions include a constant, interview noise controls and country dummies (not reported). Robust standard errors, clustered by 4 -digit NACE sector, in parentheses. Asterisks indicate statistical significance at the $10 \%(*), 5 \%(* *)$ and $1 \%(* * *)$ level.

\subsection{A regression based test}

If $\mathrm{CI}$ and $\mathrm{TI}$ are accurate measures of relocation risk, they should be positively correlated with VS. We implement this test in the regression

$$
V S_{i, s}=\beta_{0}+\beta_{T} T I_{s}+\beta_{C} C I_{s}+\mathbf{x}_{\mathbf{i}, s}^{\prime} \beta_{\mathbf{x}}+\varepsilon_{i, s}
$$

where $V S_{i, s}$ is the vulnerability score of firm $i$ in sector $s, T I_{s}$ and $C I_{s}$ are the EC's trade and carbon criteria at the sector level, and $\mathbf{x}_{i, s}$ is a vector including higher order terms of these variables, country dummies, and interview noise controls.

Table 7 summarizes the results of various specifications of this regression. In the univariate specifications, we find a strong positive association of vulnerability with 
CI but no statistically significant association with TI. This result is robust when both measures are included in a quadratic form that is better suited to capture possible effects of interactions and non-linearities. For instance, trade exposure could matter for very high values of TI only, or only when it coincides with high CI. There is no evidence of such effects. Weighting the regression equation (11) by employment does not change the qualitative findings but gives rise to a larger estimate for the impact on CI. This suggests that CI is a particularly good measure of the risk of downsizing among large firms. In sum, our regression-based test reveals that TI is not a good indicator to measure the risk of downsizing or outsourcing whereas CI is.

It could be argued that the continuous relationship between VS, CI and TI imposed in these regressions is not appropriate for the EC's threshold based approach. We thus modify equation (11) to include a set of dummy variables representing the exemption categories $(A, B, C)$ defined above instead of the continuous variables $T I$ and $C I$. The results are reported in the first column of Table 8. Only the very carbon intensive group (A) has an average VS significantly higher than the reference category (firms that are not exempt from auctioning). But even in group $A$ there is no dramatically high risk of downsizing or outsourcing for the average firm. The $95 \%$-confidence band for the VS in group $A$ just about includes the value of 3 , which means a reduction of at least $10 \%$ in production or employment due to outsourcing.

\subsection{Two simple modifications}

The above results suggest that the efficiency of the allocation scheme could be enhanced if the exemption criteria or associated thresholds were modified so as to better reflect the true risk of carbon leakage. Two simple modifications to the EU criteria 
could be proposed along those lines.

Modifying intensity thresholds The result that the average VS in categories $B$ and $C$ is not significantly higher than in sectors not exempt from auctioning suggests that subjecting sectors in these categories to auctioning would not raise overall relocation risk. However, category $B$ is very heterogeneous. While most sectors in this category are not carbon intensive at all $(C I<5)$, there is a small number of sectors with intermediate CI $(5<C I<30)$, as shown in Figure 1. In order to account for this heterogeneity, we subdivide category $B$ into a group with low $\mathrm{CI}(B \cap C I<5)$ and one with intermediate $\mathrm{CI}(B \cap C I>5)$.

When these separate groups are included along with groups $A$ and $C$ in regression equation (11), the more carbon-intensive sectors in group $B$ exhibit a significantly higher risk of outsourcing than the reference group, even though, as is the case for group $A$, the risk of downsizing or closure does not attain dramatically high levels for the average firm (cf. columns 2 and 3 of Table 8). This result holds up when the regression is weighted by employment. In fact, the coefficient estimates on groups $A$ and $B \cap C I>5$ both become stronger, indicating that some of the larger firms in those categories are at a higher risk. In order to account for the qualitative difference between a slight increase in downsizing risk and a strong downsizing impact, we also estimate Probit regressions of the binary event that a firm has a VS of 3 or larger. The results, reported in columns 4 and 5 of Table 8 , confirm that only groups $A$ and $B \cap C I>5$ present some risk of downsizing. Adjusting the thresholds for exemption in this way would increase the efficiency of the allocation process. ${ }^{38}$

\footnotetext{
${ }^{38}$ Table E.4 in the Appendix lists all sectors that would cease to be exempt from auctioning under this proposal.
} 
Table 9: Regressions of the vulnerability score on CI and region specific TI

\begin{tabular}{|c|c|c|c|}
\hline & (1) & (2) & (3) \\
\hline & \multicolumn{3}{|c|}{ Vulnerability Score } \\
\hline \multirow[t]{2}{*}{ Sectoral Carbon Intensity (CI) } & $0.234 * * *$ & $0.547 * * *$ & $0.551 * * *$ \\
\hline & $(0.060)$ & $(0.169)$ & $(0.166)$ \\
\hline \multirow{2}{*}{$\begin{array}{l}\text { Sectoral Trade Intensity (TI) } \\
\text { with LESS developed countries }\end{array}$} & $0.376^{* *}$ & $0.695 * * *$ & $1.454 * * *$ \\
\hline & $(0.164)$ & $(0.232)$ & $(0.245)$ \\
\hline \multirow[t]{2}{*}{ TI with LEAST developed countries } & $-0.228 * * *$ & $-0.422 * * *$ & $-0.740 * * *$ \\
\hline & $(0.076)$ & $(0.157)$ & $(0.174)$ \\
\hline \multirow{2}{*}{ TI with Developed non-EU countries } & 0.117 & -0.216 & $-0.593 * * *$ \\
\hline & $(0.125)$ & $(0.243)$ & $(0.219)$ \\
\hline \multirow[t]{2}{*}{ TI with EU countries } & $-0.229 * *$ & $-0.411 * * *$ & $-0.680 * * *$ \\
\hline & $(0.114)$ & $(0.143)$ & $(0.190)$ \\
\hline Quadratic terms & no & yes & yes \\
\hline Interaction terms & no & yes & yes \\
\hline Weights & no & no & employment \\
\hline Observations & 389 & 389 & 389 \\
\hline
\end{tabular}

Notes: OLS regressions in columns 1 and 2. WLS regression in column 3. The dataset is a cross section of 389 interviewed firms that are part of the EU ETS and for which CITL data, carbon intensity data and geographically precise sectoral trade and carbon intensity data are available. Robust standard errors, clustered by 4-digit NACE sector, in parentheses. Asterisks indicate statistical significance at the $10 \%(*), 5 \%(* *)$ and $1 \%(* * *)$ level. Includes a constant, country dummies and interview noise controls (not reported). The dependent variable is the vulnerability score of the firm given by the interviews data. As explanatory variables, CI indicates carbon intensity and TI trade intensity which are calculated from Eurostat and the EU Commission data.

Refining the trade intensity definition The evidence shows that the TI criterion is of limited value in proxying a sector's actual downsizing risk. One reason for this could be that this indicator is not precise enough to capture how exposure to international markets might affect downsizing risk. For example, being exposed to competition from China might affect a firm's competitiveness in a very different way than does competition from Australia. Moreover, being export intensive could have different implications than being import intensive. In order to explore whether a refined TI measure would give a better indicator of carbon leakage risk, we regress VS on CI and four separate measures of the intensity of trade with (i) least developed countries (according to the UN classification), (ii) less developed (or developing) countries including China and India, (iii) developed-non EU countries and (iv) EU countries.

Table 9 summarizes the main results of these regressions. Column 1 reveals a 
strong positive association between vulnerability and TI with less developed countries, which includes China and other countries that compete with European manufacturing firms and tend to have less stringent environmental regulation standards. The relationship between vulnerability and TI with least developed countries is negative and significant. This could reflect a lack of competition from such countries as they tend to export agricultural products and natural resources rather than manufactured goods. High TI with EU countries is negatively associated with the VS. This is consistent with firms anticipating that their EU competitors will be subject to the same policy constraints. The findings obtained in the quadratic form, which includes interactions of TI with CI and squared terms, are qualitatively similar (column 2). ${ }^{39}$ The weighted regression shows that especially the large firms in sectors that have a high TI with less developed countries are relatively more at risk of downsizing (column 3). The coefficients on TI with other regions are negative. ${ }^{40}$ In sum, these results support the adoption of a more specific TI measure, calculated on the basis of trade flows between the EU and less developed countries.

\subsection{Foregone auction revenue}

If exemptions from permit auctioning were granted according to the modified criteria considered in the previous section, more emission permits could be auctioned without a significant increase in leakage risk. For a back-of-the-envelope calculation of

\footnotetext{
${ }^{39}$ In addition, TI with other developed countries outside the EU only matters in interaction with high CI, in which case vulnerability is lower. Conversely, the negative link between vulnerability and TI for the least developed countries is partially offset for the most carbon intensive firms. See Table E.2 in the Appendix for the coefficients on all interaction and squared terms.

${ }^{40}$ In further specifications (reported in Table E. 3 of the Appendix), we decompose the TI measure into export intensity and import intensity. This does not yield more significant results than for the overall TI measure. After differentiating trade intensities by region as above, we find that exports and imports to less developed countries are both positively associated with VS.
} 
the resulting increase in auction revenue, we compile installation-level data on benchmarking allocations, available for 22 countries, and match in the information on the NACE industry code, which is needed to assign installations to exemption groups. ${ }^{41}$ The amount of emissions no longer exempt from auctioning under an alternative rule is computed taking into account that installations in non-exempt sectors get free permits for only $80 \%$ instead of $100 \%$ of their benchmark emissions in 2013 , and that this proportion falls linearly to $30 \%$ until 2020 . For the modification of the intensity thresholds described above, an additional 82.3 million tons could be auctioned in our sample, as is shown in the first row of Table 10. This number is a lower bound as it does not include (i) a small proportion of installations that could not be matched to industry codes and (ii) installations in seven countries for which the NIM data were not publicly available ${ }^{42}$. Using aggregate data on emissions in 2009, we scale up the initial estimate to the entire EU ETS and obtain a total of 100.3 million permits to be auctioned. ${ }^{43}$ Thanks to our large sample of installations, the bootstrapped $95 \%$ confidence intervals around these point estimates are quite tight. Finally, we translate emissions into revenues using two alternative allowance prices. The higher price of $€ 30$ is considered in keeping with the EU Commission (2009). A lower price of $€ 5$ is closer to the market price observed during 2012 and 2013. This leads to an estimate of additional auction revenue of either $€ 0.5$ or $€ 3$ billion per year, with uncertainty of

\footnotetext{
${ }^{41}$ We thank Oliver Sartor, Stephen Lecourt and Clément Pallière for kindly providing us with the data for 20 of these countries, for which they collected and matched the NIM data on free permit allocation to ORBIS (see Lecourt et al., 2013). We complemented this dataset with the NIM data for Belgium and Hungary, which we matched to ORBIS by hand. In total, this results in a sample of nearly 8,000 installations covering $95 \%$ of the emissions.

${ }^{42}$ The Czech Republic, Latvia, Liechtenstein, Lithuania, Malta, Norway and Slovenia.

${ }^{43}$ This is done in two steps. First, for each CITL sector in each of the 22 countries, extra auctioning is scaled up by the proportion of matched 2009 allocations for the respective sector-country pair. Second, for each CITL sector, additional auctioned permits were divided by the share of the 22 countries in the total, EU ETS wide allocation for that sector in 2009.
} 
Table 10: Reduction of free permit allocation and additional revenue

\begin{tabular}{lcccc}
\hline \hline & $\begin{array}{c}\text { Reduction of free } \\
\text { permit allocation } \\
(22 \text { countries }) \\
{\left[\mathrm{MtCO}_{2} \text { eq }\right]}\end{array}$ & $\begin{array}{c}\text { Reduction of free } \\
\text { permit allocation, } \\
\text { whole EU ETS } \\
{\left[\mathrm{MtCO}_{2} \text { eq }\right]}\end{array}$ & $\begin{array}{c}\text { Additional revenue } \\
\text { with price of } € 30 \text { per } \\
\text { ton }[\mathrm{M} €]\end{array}$ & $\begin{array}{c}\text { Additional revenue } \\
\text { with price of } € 5 \\
\text { per ton }[\mathrm{M} €]\end{array}$ \\
$A$ and $B \& C I>5$ & 82.27 & 100.29 & $3,008.78$ & 501.46 \\
& {$[70.78 ; 95.54]$} & {$[86.51 ; 115.54]$} & {$[2,595.35 ; 3,466.17]$} & {$[432.56 ; 577.69]$} \\
$\begin{array}{l}A, B \text { and } C-\text { but TI with less } \\
\text { developed countries only }\end{array}$ & 8.29 & 14.35 & 430.4 & 71.73 \\
\hline \hline
\end{tabular}

Notes: Each row reports the reduction of free permit allocations and additional revenue under a different rule. A, B and C refer to the EU criteria defined in Section 2.2. The second row uses trade intensity (TI) with less developed countries in the definition of groups $\mathrm{B}$ and $\mathrm{C}$. MtCO2eq stands for million metric tons of $\mathrm{CO}_{2}$ equivalent. The numbers in brackets report two-sided $95 \%$ confidence intervals of the reductions of free permit allocation and additional revenue obtained from a bootstrap with 200 replications.

$\pm 15 \%$.

When the exemption categories are maintained but TI with less developed countries is used instead of overall TI, the increase in auction revenue is lower $-€ 71$ to $€ 430$ million per year, depending on the allowance price - and estimated somewhat less precisely. While these revenue estimates are also subject to uncertainty about future carbon emissions and allowance prices, their order of magnitude shows that the EU is prepared to hand out profit subsidies to polluting firms on an enormous scale without getting anything in return. Instead, these monies could be used to fund infrastructure or R\&D relevant for GHG abatement as well as to compensate lower income groups for the likely regressiveness of higher energy prices due to carbon pricing.

\section{Conclusion}

When governments intervene in markets to regulate negative externalities, industry associations often demand compensation for the adverse impact of regulation on their international competitiveness. If firms are to carry the full burden of regulation, so 
the argument goes, they have no choice but to relocate to an unregulated jurisdiction. From the government's perspective, relocation is undesirable because firms take with them jobs, taxable profits and - in the case of climate policy - the very emissions targeted by the regulation. We have analyzed an industry compensation scheme aimed at minimizing the expected damage of such extensive-margin responses to regulation. This simple economic criterion requires that compensation be distributed across firms so as to equalize the expected marginal impact of relocation on the regulator's objective function.

We have applied this idea in the context of the EU ETS, where industry compensation is given in the form of free permit allocations, with the stated objective to prevent relocation and carbon leakage. Our analysis has shown that the criteria adopted by the EC to establish the risk of carbon leakage give rise to inefficient allocations. Optimal allocation yields drastic reductions in job risk, and so do simple approximations to the optimal allocation based on easily observable firm characteristics. Conversely, aggregate relocation risk induced by current compensation rules could be maintained while handing out far less permits for free and selling more of them in permit auctions. This would generate additional auction revenue at a social cost much lower than that of alternative ways of raising public funds.

Our numerical analysis takes the EU's stated objective to prevent relocation and carbon leakage at face value. The benefit of this normative approach is that it highlights exactly how and by how much the implemented allocation rules deviate from a precisely-defined policy goal. This benefit extends beyond the European policy context, as similar compensation principles have been adopted by other carbon trading schemes worldwide. It stands to reason, however, that 'unofficial' policy objectives behind the free allocation scheme were more nuanced. For instance, free allocation is 
often used to build political support among large polluters in the initial stages of a capand-trade program. Future research could address these factors in the framework of a positive analysis of distributional aspects and the political economy of free permit allocation. Such an analysis might also take into account possible benefits of relocation, such as a reduction in subsidy payments or in local pollution levels.

The compensation principle proposed here also motivates further research into firms' relocation propensities under different allocation rules. This research could follow a variety of approaches, ranging from the econometric analysis of observed exit patterns to the design of a mechanism that implements optimal compensation.

\section{References}

Abrell, J., Ndoye, A., and Zachmann, G. (2011). Assessing the impact of the EU ETS using firm level data. Bruegel Working Paper 2011/08, Brussels, Belgium.

Anger, N., and Oberndorfer, U. (2008). Firm performance and employment in the EU emissions trading scheme: An empirical assessment for Germany. Energy Policy, $36(1), 12-22$.

Bertrand, M., and Mullainathan, S. (2001). Do People Mean What They Say Implications for Subjective Survey Data. American Economic Review, 91(2), 67-72.

Bloom, N., Genakos, C., Martin, R., and Sadun, R. (2010a). Modern Management: Good for the Environment or Just Hot Air? The Economic Journal, 120(544), 551572.

Bloom, N., and van Reenen, J. (2007). Measuring and Explaining Management Practices across Firms and Countries. Quarterly Journal of Economics, CXXII(4), 13511406.

Bloom, N., and van Reenen, J. (2010). New Approaches to Surveying Organizations. American Economic Review, 100(2), 105-09.

Blundell, R., and Bond, S. (1998). Initial conditions and moment restrictions in dynamic panel data models. Journal of Econometrics, 87(1), 115-143. 
Bovenberg, A. L., and Goulder, L. H. (2002). Neutralizing the Adverse Industry Impacts of $\mathrm{CO} 2$ Abatement Policies: What Does It Cost? In C. Carraro, and G. Metcalf (Eds.) Behavioral and Distributional Effects of Environmental Policy. Chicago, IL: University of Chicago Press.

Bovenberg, A. L., Goulder, L. H., and Gurney, D. J. (2005). Efficiency Costs of Meeting Industry-Distributional Constraints Under Environmental Permits and Taxes. RAND Journal of Economics, 36(4), 950-970.

Bovenberg, A. L., Goulder, L. H., and Jacobsen, M. R. (2008). Costs of alternative environmental policy instruments in the presence of industry compensation requirements. Journal of Public Economics, 92(5-6), 1236-1253.

Burtraw, D., Palmer, K., Bharvirkar, R., and Paul, A. (2001). The effect of allowance allocation on the cost of carbon emission trading. RFF discussion paper 01-30.

Bushnell, J. B., and Chen, Y. (2009). Regulation, Allocation, and Leakage in Cap-andTrade Markets for CO2. Tech. Rep. 15495, National Bureau of Economic Research.

Bushnell, J. B., Chong, H., and Mansur, E. T. (2012). Profiting from Regulation: Evidence from the European Carbon Market. American Economic Journal: Economic Policy, forthcoming.

Calel, R., and Dechezleprêtre, A. (2012a). Environmental Policy and Directed Technological Change: Evidence from the European Carbon Market. Discussion Paper 1141, CEP.

Clò, S. (2010). Grandfathering, auctioning and Carbon Leakage: Assessing the inconsistencies of the new ETS Directive. Energy Policy, 38(5), 2420-2430.

Commins, N., Lyons, S., Schiffbauer, M., and Tol, N. C. (2011). Climate Policy and Corporate Behavior. The Energy Journal, 32(4).

Demailly, D., and Quirion, P. (2006). CO2 abatement, competitiveness and leakage in the European cement industry under the EU ETS: grandfathering versus outputbased allocation. Climate Policy, 1, 93-113.

Demailly, D., and Quirion, P. (2008). European Emission Trading Scheme and competitiveness: A case study on the iron and steel industry. Energy Economics, 30(4), 2009-2027.

Ellerman, A. D. (2008). New Entrant and Closure Provisions: How do they Distort? The Energy Journal, 29(Special Issue), 63-76. 
Ellerman, A. D., Buchner, B. K., and Carraro, C. (Eds.) (2007). Allocation in the European Emissions Trading Scheme: Rights, Rents and Fairness. Cambridge: Cambridge University Press.

Ellerman, A. D., and Joskow, P. L. (2008). The European Union's Emissions Trading System in Perspective. Tech. rep., Pew Center on Global Climate Change, Washington, DC.

EU Commission (2009). Impact Assessment accompanying the commission decision determining a list of sectors and subsectors which are deemed to be exposed to a significant risk of carbon leakage pursuant to article 10a (13) of Directive 2003/87/ec.

Fischer, C., and Fox, A. K. (2007). Output-based allocation of emissions permits for mitigating tax and trade interactions. Land Economics, 83(4), 575-599.

Fowlie, M. (2011). Updating the Allocation of Greenhouse Gas Emissions Permits in a Federal Cap-and-Trade Program. In D. Fullerton, and C. Wolfram (Eds.) The Design and Implementation of US Climate Policy, (pp. 157-171). Chicago, IL: University of Chicago Press.

Hanna, R. (2010b). US environmental regulation and FDI: evidence from a panel of US-based multinational firms. American Economic Journal: Applied Economics, 2(3), 158-89.

Hood, C. (2010). Reviewing Existing and Proposed Emissions Trading Systems. Tech. Rep. 13, International Energy Agency, Paris.

Juergens, I., Barreiro-Hurlé, J., and Vasa, A. (2013). Identifying carbon leakage sectors in the EU ETS and implications of results. Climate Policy, 13(1), 89-109.

Kenber, M., Haugen, O., and Cobb, M. (2009). The Effects of EU Climate Legislation on Business Competitiveness: A Survey and Analysis. Climate \& Energy Paper Series, The German Marshall Fund of the United States.

Lecourt, S., Pallière, C., and Sartor, O. J. (2013). The impact of emissions-performance benchmarking on free allocations in EU ETS Phase 3. Tech. Rep. 2013-02, Paris Dauphine CDC Climat.

Martin, R., de Preux, L. B., and Wagner, U. J. (2011a). The Impacts of the Climate Change Levy on Manufacturing: Evidence from Microdata. Working Paper 17446, National Bureau of Economic Research.

Martin, R., Muûls, M., De Preux, L. B., and Wagner, U. J. (2012b). Anatomy of a Paradox: Management Practices, Organizational Structure and Energy Efficiency. Journal of Environmental Economics and Management, 63(2), 208-223. 
McKinsey, and Ecofys (2006a). EU ETS REVIEW Report on International Competitiveness. Tech. rep., European Commission Directorate General for Environment, Brussels.

McKinsey, and Ecofys (2006b). Review of Emissions Trading Scheme: Survey highlights. Tech. rep., European Commission Directorate General for Environment, Brussels.

Meunier, G., Ponssard, J.-P., and Quirion, P. (2012). Carbon Leakage and CapacityBased Allocations. Is the EU right? CESifo Working Paper Series 4029, CESifo Group Munich.

Monjon, S., and Quirion, P. (2011). Addressing leakage in the EU ETS: Border adjustment or output-based allocation? Ecological Economics, 70(11), 1957-1971.

Paltsev, S. V. (2001). The Kyoto Protocol: Regional and Sectoral Contributions to the Carbon Leakage. The Energy Journal, 22(4), 53-79.

Popp, D. (2002). Induced Innovation and Energy Prices. The American Economic Review, 92(1), 160-180.

Reinaud, J. (2005). Industrial competitiveness under the European Union Trading Scheme. Tech. rep., International Energy Agency, Paris.

Sato, M., Grubb, M., Cust, J., Chan, K., Korppoo, A., and Ceppi, P. (2007a). Differentiation and dynamics of competitiveness impacts from the EU ETS. CWPE 0712, Faculty of Economics, University of Cambridge, UK.

Smale, R., Hartley, M., Hepburn, C. J., Ward, J., and Grubb, M. (2006). The impact of $\mathrm{CO} 2$ emissions trading on firm profits and market prices. Climate Policy, 6(1), $31-48$.

Wagner, U. J., and Timmins, C. (2009). Agglomeration Effects in Foreign Direct Investment and the Pollution Haven Hypothesis. Environmental and Resource Economics, 43(2), 231-256. 